\title{
Quantitative assessment of AD markers using naked eyes: point-of-care testing with paper-based lateral flow immunoassay
}

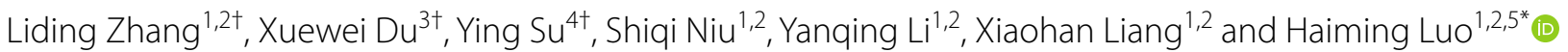

\begin{abstract}
$A \beta_{42}$ is one of the most extensively studied blood and Cerebrospinal fluid (CSF) biomarkers for the diagnosis of symptomatic and prodromal Alzheimer's disease (AD). Because of the heterogeneity and transient nature of $A \beta_{42}$ oligomers ( $A \beta_{42} \mathrm{Os}$ ), the development of technologies for dynamically detecting changes in the blood or CSF levels of $A \beta_{42}$ monomers ( $A \beta_{42} \mathrm{Ms}$ ) and $A \beta_{42} \mathrm{Os}$ is essential for the accurate diagnosis of $A D$. The currently commonly used $A \beta_{42}$ ELISA test kits usually mis-detected the elevated $A \beta_{42} O$ s, leading to incomplete analysis and underestimation of soluble $A \beta_{42}$, resulting in a comprised performance in $A D$ diagnosis. Herein, we developed a dual-target lateral flow immunoassay (dLFI) using anti-A $\beta_{42}$ monoclonal antibodies $1 F 12$ and $2 \mathrm{C} 6$ for the rapid and point-of-care detection of $A \beta_{42} \mathrm{Ms}$ and $A \beta_{42} \mathrm{Os}$ in blood samples within $30 \mathrm{~min}$ for $A D$ diagnosis. By naked eye observation, the visual detection limit of $A \beta_{42} \mathrm{Ms}$ or/and $A \beta_{42} \mathrm{Os}$ in $\mathrm{dLFI}$ was $154 \mathrm{pg} / \mathrm{mL}$. The test results for $\mathrm{dLFI}$ were similar to those observed in the enzyme-linked immunosorbent assay (ELISA). Therefore, this paper-based dLFI provides a practical and rapid method for the on-site detection of two biomarkers in blood or CSF samples without the need for additional expertise or equipment.
\end{abstract}

Keywords: Alzheimer's disease, Blood, $A \beta_{42}$ monomer, $A \beta_{42}$ oligomer, Magnetic nanoparticles, Gold nanoparticle, Paper-based lateral flow immunoassay

*Correspondence: hemluo@hust.edu.cn

†Liding Zhang, Xuewei Du and Ying Su contributed equally to this work

${ }^{5}$ Wuhan, China

Full list of author information is available at the end of the article

(c) The Author(s) 2021. Open Access This article is licensed under a Creative Commons Attribution 4.0 International License, which permits use, sharing, adaptation, distribution and reproduction in any medium or format, as long as you give appropriate credit to the original author(s) and the source, provide a link to the Creative Commons licence, and indicate if changes were made. The images or other third party material in this article are included in the article's Creative Commons licence, unless indicated otherwise in a credit line to the material. If material is not included in the article's Creative Commons licence and your intended use is not permitted by statutory regulation or exceeds the permitted use, you will need to obtain permission directly from the copyright holder. To view a copy of this licence, visit http://creativecommons.org/licenses/by/4.0/. The Creative Commons Public Domain Dedication waiver (http://creativeco mmons.org/publicdomain/zero/1.0/) applies to the data made available in this article, unless otherwise stated in a credit line to the data. 


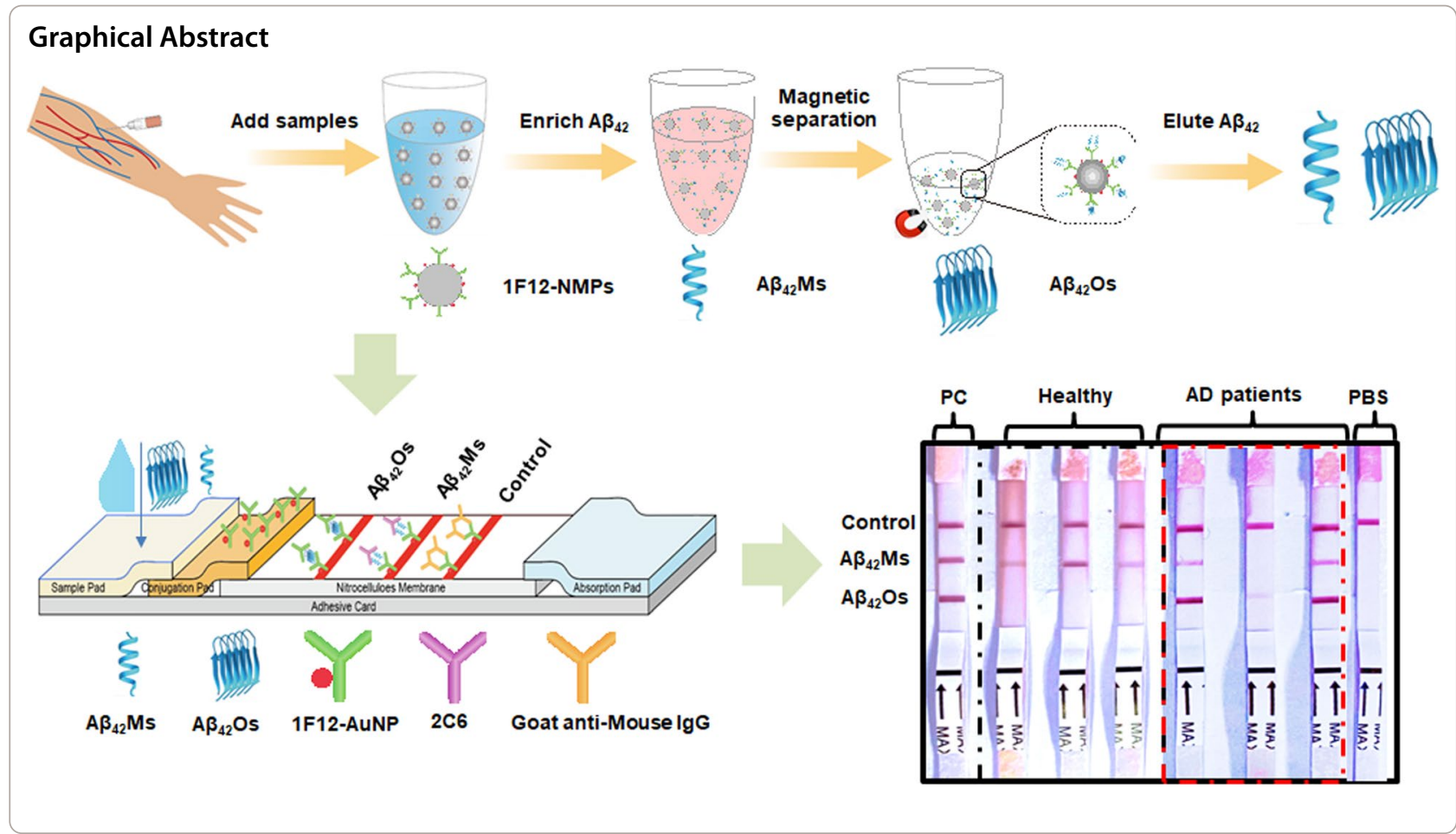

\section{Introduction}

Alzheimer's disease (AD) is a chronic neurodegenerative disorder, which may begin to develop 20-30 years before clinical onset, accompanied by progressive neuropathology, brain atrophy, and ultimately lead to cognitive decline [1-3]. By 2050, the number of AD worldwide will increase from the estimated 50 million reported in 2018 to 152 million [4]. Current treatment strategies for $\mathrm{AD}$ are limited to symptom relief $[5,6]$. There is an urgent need to develop practical diagnostic tools and conduct large-scale early prevention and screening of high-risk groups to solve the public health crisis caused by AD. Presently, the diagnosis of AD is still mainly based on clinical cognitive assessment and physical examination. Histopathological examination of brain autopsy specimens is the only way to diagnose definite AD. Although the exact mechanism of $A D$ pathogenesis remains elusive, amyloid $\beta(A \beta)$ has been proposed to be an essential biomarker and therapeutic target for AD [7-9]. To date, magnetic resonance imaging (MRI) for measuring brain volume and neuronal connections, and $\mathrm{A} \beta$ - or taubased positron-emission tomography (PET) for detecting pathological protein deposition in the brain have been used in AD diagnosis [10-13]. Although MRI and PET imaging tools with good diagnostic performances of brain diseases are approved for clinical use, the economic burden of imaging hinders their wide application in the identification of AD [14]. In addition, limited MRI or
PET equipment is difficult to meet the growing number of $\mathrm{AD}$ patients. Expect for imaging diagnosis tools, it has also developed the detection of cerebrospinal fluid (CSF) biomarkers, such $A \beta_{1-40}\left(A \beta_{40}\right), A \beta_{1-42}\left(A \beta_{42}\right)$, and the phosphorylation of tau (p-Tau) for AD diagnosis. Among them, the $A \beta$-based ELISA methods have been used as a reference for clinical diagnosis [15-17].

$\mathrm{A} \beta$ is a $38-43$ amino acid polypeptide derived from amyloid precursor protein that is continuously cleaved by $\beta$ - and $\gamma$-secretase. The predominant $A \beta$ subtypes are $A \beta_{40}$ and $A \beta_{42}$, of which $A \beta_{42}$ is easier to form fibrils and has a stronger tendency to aggregate. Increasing evidence has implicated that soluble $A \beta_{42}$ oligomers $\left(A \beta_{42} \mathrm{Os}\right)$ are the most critical toxic species causing AD-related synapse/neuron loss $[18,19]$ and memory decline [20]. $A \beta_{42}$ monomers $\left(\mathrm{A} \beta_{42} \mathrm{Ms}\right)$ can modulate the $\mathrm{A} \beta$ self-assembly process to maintain intracellular signal transduction to achieve synaptic plasticity and homeostasis [21]. Therefore, both $A \beta_{42}$ Os and $A \beta_{42}$ Ms are related to the pathogenesis of $\mathrm{AD}$. Abnormal $\mathrm{A} \beta_{42}$ levels can be detected in CSF and amyloid- $\beta$ PET neuroimaging (amyloid-PET) [22-24]. However, there are some limitations, such as high testing costs, limited equipment, and invasiveness [25]. Compared with CSF measurements that may cause lumbar puncture and back pain, blood-related diagnosis tools are more acceptable due to their ease of collection, less invasiveness, and low cost. Multiple evidence shows that $A \beta$ appearing in human blood [26-28] may 
be transmitted by peripheral monocytes [29], axonal [30, $31]$, exosomes $[32,33]$ from the brain over the bloodbrain barrier. Furthermore, changes in the increased $\beta$-sheet structure of $A \beta$ in human blood are associated with $\mathrm{AD}$ biomarkers in cerebrospinal fluid (CSF) and amyloid-PET [27]. Dynamic monitoring of $\mathrm{A} \beta_{42} \mathrm{Ms}$ and $A \beta_{42}$ Os levels in the blood helps to accurately diagnose AD before clinical symptoms appear.

Many attempts have been made to explore new diagnostic tools for several core biomarkers, including enzyme-linked immunosorbent assay (ELISA) [34-36], nanoparticle-based immunoassays [37], electrochemistry [38], surface-enhanced Raman spectroscopy [39, 40], fluorescence [41], and electrochemical biosensors [42, 43]. However, due to the heterogeneity and transient nature of $A \beta$ oligomers, most of these assays not only cannot distinguish between $A \beta_{42}$ Os and $A \beta_{42}$ Ms but also require equipment or/and expertise. The development of technologies that can dynamically detect changes in the levels of $A \beta_{42}$ Ms and $A \beta_{42}$ Os in the blood is essential for the accurate diagnosis of AD.

Paper-based lateral flow immunoassay (LFI) has been widely used for the rapid diagnosis of blood biomarkers due to its simplicity, portability, cost-effectiveness, and rapid detection of target biomarkers [44-47]. However, the accuracy and sensitivity of LFIS to a single biomarker still need to be improved, especially in the face of complicated pathological diseases such as $\mathrm{AD}$ with multiple biomarkers, including $A \beta_{42} \mathrm{Ms}, A \beta_{42} \mathrm{Os}, \mathrm{p}$-Tau ${ }^{181}$, and $\mathrm{p}-\mathrm{Tau}^{217}$. Currently, diagnostic tools for AD mainly target one biomarker, such as $\mathrm{A} \beta$, $\mathrm{p}$-Tau, or total tau, with compromised sensitivity and specificity. Previous studies reported that the average specificities of AD diagnostic methods based on $\mathrm{A} \beta$, $\mathrm{t}$-tau, or $\mathrm{p}$-tau are $84.1 \%$, $82.3 \%$, and $83 \%$, while their average sensitivities were $79.4 \%, 80.5 \%$, and $78.3 \%$ [48-50]. However, the average specificity and sensitivity of multi-biomarker-based detection methods are over $86 \%$ and $83.5 \%$, which are relatively higher than those based on a single biomarker $\mathrm{A} \beta$, p-Tau, or total tau [48-50]. Recently, we screened the preferred antibody pairs $1 \mathrm{~F} 12 / 1 \mathrm{~F} 12$ and $1 \mathrm{~F} 12 / 2 \mathrm{C} 6$ to achieve accurate detection of $\mathrm{A} \beta_{42} \mathrm{Ms}$ and $\mathrm{A} \beta_{42} \mathrm{Os}$. The strategy used in our previous study for the detection of oligomeric and monomeric $A \beta$ was to use the antibody $1 \mathrm{~F} 12$ with a single epitope to capture $A \beta_{42} \mathrm{Ms}$ and $A \beta_{42}$ Os and then incubated with the detection antibody $1 F 12$ with the same epitope for detecting only oligomers because oligomers were aggregated by multiple monomers, exposing several identical epitopes that can be recognized by the same detection antibody. While for $A \beta_{42}$ Ms, they were only detected by the antibody $2 \mathrm{C} 6$ with different epitopes from the capture antibody $1 F 12$ to form a sandwich structure [51]. In addition, our analysis of the levels of $A \beta_{42} \mathrm{Ms}$ and $A \beta_{42} \mathrm{Os}$ in brain and blood samples was closely related to the progression of $\mathrm{AD}$, indicating that simultaneous detection of $\mathrm{A} \beta_{42} \mathrm{Ms}$ and $A \beta_{42}$ Os may improve the specificity and sensitivity of $\mathrm{AD}$ detection [51]. Given that, we look forward to developing a test strip that can accurately detect the levels of $\mathrm{A} \beta_{42} \mathrm{Ms}$ and $\mathrm{A} \beta_{42} \mathrm{Os}$ in the blood to achieve a rapid and accurate diagnosis of AD. In this study, we developed a dual-target lateral flow immunoassay (dLFI) by adopting $\mathrm{A} \beta_{42}$-specific monoclonal antibodies 1F12 and 2C6 with unique/overlapping epitopes to create steric hindrance between antibody capture and detection. Herein, 1F12 was labeled with gold nanoparticles (1F12-AuNP) as the capture antibody. Then, $1 \mathrm{~F} 12$ and $2 \mathrm{C} 6$ were used as detection antibodies to be immobilized on nitrocellulose (NC) membrane as two test lines, and goat anti-mouse IgG was immobilized on one end of the NC membranes as a control line. The clinical manifestations of dLFI were tested in blood samples of 5xFAD mice and AD patients. We aimed to develop a multi-objective LFI for rapid and high-performance diagnosis of AD.

\section{Materials and methods Materials}

A $\beta_{42}$ (DAEFRHDSGYEVHHQKLVFFAEDVGSNKGAIIG LMVGGVVIA), $A \beta_{40}$ (DAEFRHDSGYEVHHQKLVFFAEDVGSNKGAIIGLMVGGVV), P-Tau ${ }^{396,404}$ (RENAKAKTDHGAEIVYK-[Ser(P)]PVVSGDT[Ser(P)]PRHL),Cis-Tau (KVAVVRpT(5,5-dimethyl-L-proline)PKSPS), and P-Tau ${ }^{231}$ (KVAVVRpTAPKSPS) were custom-synthesized as lyophilized powders by Royo Biotech Co., Ltd (Shanghai, China) with a purity of $>95 \%$. The detailed information of synthesized peptides, including HPLC and mass spectrometry results, are shown in Additional file 1: Fig. S1-3. The $A \beta_{42}$-specific monoclonal antibodies (mAbs) $1 \mathrm{~F} 12$ and $2 \mathrm{C} 6$ were produced in our laboratory, of which the epitope of $1 \mathrm{~F} 12$ is $A \beta_{3-9}$, while the epitopes of $2 \mathrm{C} 6$ are $A \beta_{3-9}, A \beta_{13-19}, A \beta_{18-25}, A \beta_{29-36}$, and $\mathrm{A} \beta_{36-42}$ [51]. Trisodium citrate dehydrates $\left(\mathrm{HAuCl}_{4}\right)$ and bovine serum albumin (BSA) were purchased from Sigma Aldrich (St. Louis, MO, USA). $\mathrm{NaCl}$, polyvinyl pyrrolidone (PVP), K-40, sucrose, Casein, $\mathrm{NaN}_{3}$, PEG, Tris, MES, and Tween-20 were obtained from Beijing Biotopped Science and Technology Co., Ltd. (Beijing, China). Filter paper and semi-rigid polyvinyl chloride (PVC) sheets were purchased from Jieyi Biological Technology Co., Ltd. (Shanghai, China). Glass fibre membranes and nitrocellulose membranes were obtained from Millipore (Billerica, MA, USA). Goat anti-mouse IgG and protein A resins were purchased from GenScript (Nanjing, China). N-Hydroxysuccinimide (NHS) modified magnetic nanoparticles 
were obtained from LinkedIn Biotechnology Co., Ltd. (Shanghai, China).

\section{Preparation of gold nanoparticles (AuNP)}

AuNP was synthesized following the $\mathrm{HAuCl}_{4}$ reduction scheme with citric acid [52]. Briefly, $99 \mathrm{~mL}$ of ultrapure water was added to a purified bottle, and $1 \mathrm{~mL}$ of $1 \%$ $\mathrm{HAuCl}_{4} \cdot 3 \mathrm{H}_{2} \mathrm{O}$ was then added with continuous stirring and heating. The solution was heated until the solution started to boil slightly, and $1 \mathrm{~mL}$ of filtered $1 \%$ trisodium citrate solution was then added. After heating for a few minutes, the solution gradually changed from colorless to grey, black, purple, and red. The heating was then stopped, and the solution was continuously shaken slowly until it cooled.

\section{Preparation of 1F12-conjugated AuNP and magnetic nanoparticles}

AuNP were synthesized using the citrate reduction as per the $\mathrm{HAuCl}_{4}$ protocol [52]. First, 1F12 antibody was purified with protein A immunoaffinity column, and conjugated to AuNP according to the following steps: (1) $1 \mathrm{~mL}$ of AuNP was added to a $1.5 \mathrm{~mL}$ centrifuge tube, followed by the addition of $16 \mu \mathrm{L}$ of $0.1 \mathrm{M} \mathrm{K}_{2} \mathrm{CO}_{3}$ with thorough mixing; (2) $25 \mu \mathrm{g}$ of $1 \mathrm{~F} 12$ was added to the mixture for $15 \mathrm{~min}$, keeping it undisturbed for another $15 \mathrm{~min}$ at $25^{\circ} \mathrm{C}$; (3) $10 \mu \mathrm{L}$ of $10 \% \mathrm{BSA}$ was added to the mixture with shaking for $15 \mathrm{~min}$ and the mixture was then kept undisturbed for $15 \mathrm{~min}$ at $25^{\circ} \mathrm{C}$ to achieve a sealing effect on the surface of AuNP; (4) the mixture was centrifuged at $13,500 \mathrm{rpm}$ for $10 \mathrm{~min}$, and the precipitate was collected to resuspend in $1 \mathrm{~mL}$ of PBS $(0.01 \mathrm{M}, \mathrm{pH} 7.4$, including $0.03 \%$ Tris, $2 \%$ Sucrose, $0.2 \%$ Casein, 1\% BSA, 0.1\% PVP, $1 \% \mathrm{NaN}_{3}, 0.1 \%$ PEG, $0.05 \%$ Tween-20) and stored at $4{ }^{\circ} \mathrm{C}$ for further use.

Further, 1F12-conjugated magnetic nanoparticles (1F12-MNPs) were prepared by making the amino group of $1 \mathrm{~F} 12$ react with the carboxyl group of MNPs, as we previously described [53]. Briefly, $1 \mathrm{~mL}$ MNPs (10 mg) was washed twice with $1 \mathrm{~mL}$ deionized water followed to wash with 4-Morpholineethanesulfonic acid (MES) buffer (0.02 M MES, pH5.0). Then, the MNPs were resuspended in $200 \mu \mathrm{L}$ of MES buffer and then $300 \mu \mathrm{g}$ of $1 \mathrm{~F} 12$ $(200 \mu \mathrm{L})$ was added for $30 \mathrm{~min}$ reaction at $25^{\circ} \mathrm{C}$ in shaking. Next, $100 \mu \mathrm{L}$ of freshly prepared EDC- $\mathrm{HCl}$ buffer (52.2 mM, dissolved in 0.02 M MES, pH5.0) was added to react in shaking overnight, followed to be blocked with blocking buffer (1\% BSA dissolved in 0.02 M MES, pH5.0). Finally, the prepared 1F12-MNPs were stored in the storage buffer (PBS containing 0.1\% Tween-20 and $0.02 \% \mathrm{NaN}_{3}, \mathrm{pH} 7.4$ ) at $4^{\circ} \mathrm{C}$ for further use. The prepared antibody-modified MNPs were evaluated via reduced tris-tricine SDS-polyacrylamide gel electrophoresis (SDS-PAGE), ELISA, and immunoprecipitation followed with Western blotting (IP-Western blotting).

\section{Characterization of AuNP, MNP, $A \beta_{42} \mathrm{Ms}$, and $A \beta_{42} \mathrm{Os}$}

The prepared AuNP, magnetic nanoparticle (MNP), $\mathrm{A} \beta_{42} \mathrm{Ms}$, and $\mathrm{A} \beta_{42} \mathrm{Os}$ were confirmed by transmission electron microscopy (TEM) and scanning electron microscopy (SEM), respectively. In short, a small drop of samples $(5 \mu \mathrm{L})$ was deposited onto a copper grid, and the excess liquid was removed by blotting using a filter paper, thus leaving a thin film of the solution on the grid. Subsequently, Tecnai G20 transmission electron microscope (FEI Ltd., USA) and Phenom Pharos scanning electron microscope (SEM) (Phenom Ltd., NLD) were used to characterize the morphology of the abovementioned samples. The particle size distribution and Zeta-potential of all nanoparticles were measured via dynamic light scattering (photon correlation spectroscopy) on a Zetasizer Nano-ZS90 system (Malvern Instruments, Worcestershire, UK).

\section{Immunoprecipitation and Western blotting}

The prepared $A \beta_{42}$ samples, including $A \beta_{42} \mathrm{Ms}$ and $A \beta_{42}$ Os, were incubated with 1 F12-MNPs for $30 \mathrm{~min}$ at $25^{\circ} \mathrm{C}$, and then the enriched $\mathrm{A} \beta_{42}$ was eluted with $0.1 \mathrm{M}$ glycine (pH 3.0) and denatured in loading buffer (Boster Biotech, USA) for $10 \mathrm{~min}$ at $95^{\circ} \mathrm{C}$, followed to run on a $12 \%$ reducing SDS-PAGE. The proteins were transferred onto a polyvinylidene fluoride membrane at $160 \mathrm{~mA}$ for $1 \mathrm{~h}$. The membrane was blocked with 5\% skimmed milk dissolved in PBS-T buffer, and then incubated with the primary antibody (1F12 or 2C6) and the secondary antibody HRP-conjugated goat anti-mouse IgG $(\mathrm{H}+\mathrm{L})$ in an order. The membrane was washed three times with PBS-T buffer ( $\mathrm{KCl} 2.7 \mathrm{mM}, \mathrm{KH}_{2} \mathrm{PO}_{4} 2 \mathrm{mM}, \mathrm{NaCl}$ $137 \mathrm{mM}, \mathrm{Na}_{2} \mathrm{HPO}_{4} 10 \mathrm{mM}, 0.05 \%$ Tween-20, pH 7.4) and the immunological signals were detected using the ECLsubstrate (Vazyme, China) on Tanon 5200 Muiti (Shanghai, China).

\section{ELISA}

For indirect ELISA, the wells of a 96-well plate (Corning Inc., USA) were coated with $0.5 \mu \mathrm{g} /$ well of $\mathrm{A} \beta_{42}$ overnight at $4{ }^{\circ} \mathrm{C}$. The plate was blocked with $5 \%$ skimmed milk, and then incubated with primary antibodies (1F12, AuNP-1F12, or 1F12-MNPs) and the secondary antibody HRP-conjugated goat anti-mouse IgG $(\mathrm{H}+\mathrm{L})$ in an order. The 96-well plate was washed four times with PBS-T in each step. The immunoreaction was visualized by TMB substrate solution (Tiangen Biotech, Beijing, China) and detected with an Epoch Microplate Spectrophotometer (Bio Tek, USA) at $450 \mathrm{~nm}$. 


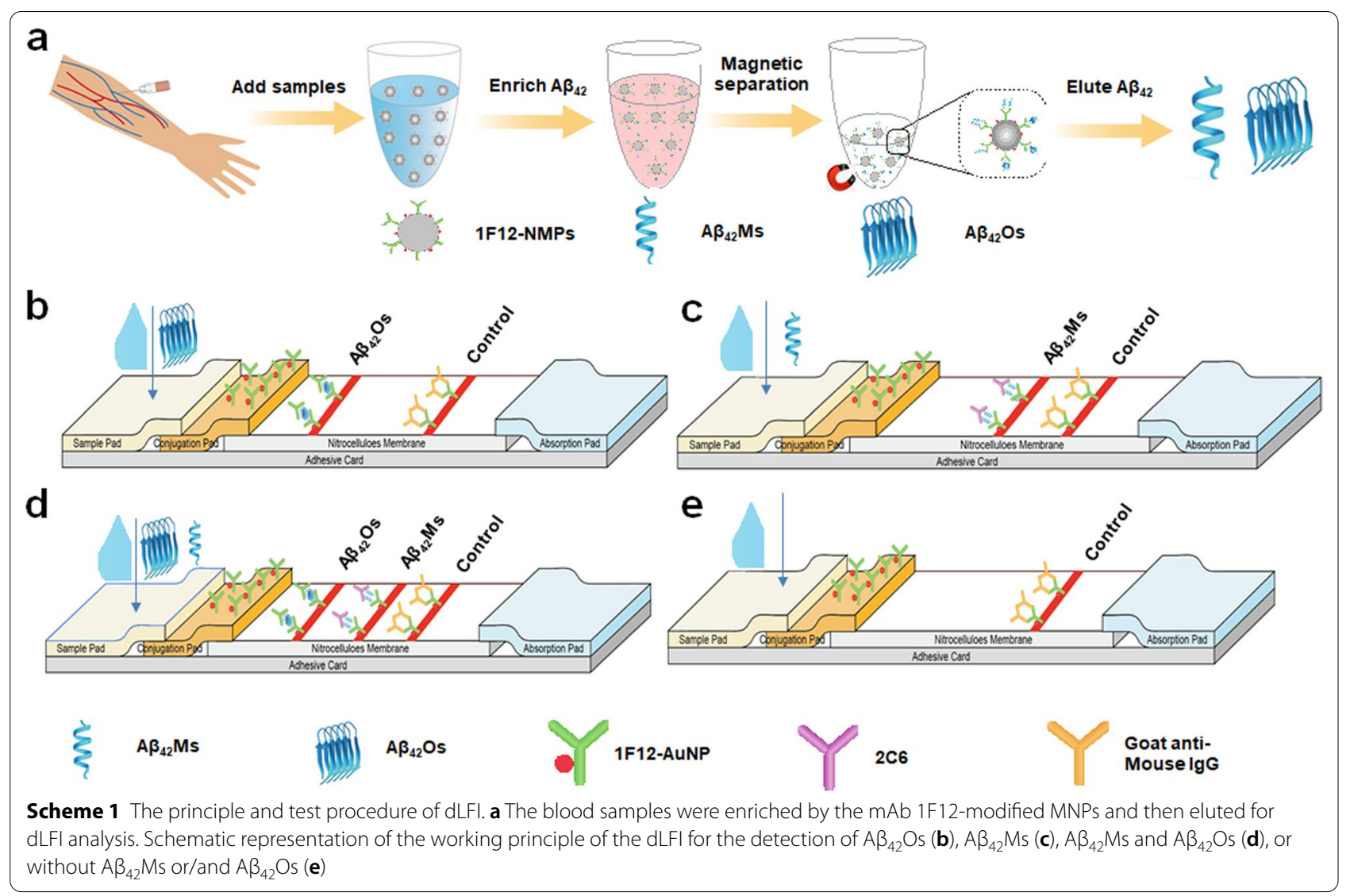

For competitive ELISA, 96-well plates were coated with $0.5 \mu \mathrm{g} \mathrm{A} \beta_{42}$ in each well and blocked with $5 \%$ skimmed milk. Triplicates of biotinylated 1F12 or 2 C6 $(250 \mathrm{ng} / \mathrm{mL})$ were mixed with serially diluted $A \beta$ preparations of $A \beta_{40}$, $\mathrm{A} \beta_{42} \mathrm{Ms}$, and $\mathrm{A} \beta_{42} \mathrm{Os}$ diluted in PBS with the final concentration from $25 \mu \mathrm{M}$ to $5 \mathrm{pM}$. After $1 \mathrm{~h}$ pre-incubation at $4^{\circ} \mathrm{C}$ in $1.5 \mathrm{~mL}$ tubes, the antibody-antigen mixtures were incubated on the $A \beta_{42}$ antigen-coated plates for $1 \mathrm{~h}$ at $25^{\circ} \mathrm{C}$. After incubating with streptavidin-coupled polyHRP, the immunoreaction was visualized and detected as above described.

\section{Immunofluorescence assay}

The $15-\mu \mathrm{m}$ coronal frozen sections of the brain tissue samples were permeabilized with $0.2 \%$ Triton X-100 for $20 \mathrm{~min}$ at $25^{\circ} \mathrm{C}$, then blocked with $3 \%$ bovine serum albumin for $2 \mathrm{~h}$, followed to incubate with $\mathrm{Cy} 3$-conjugated mAb 1F12, 2C6 and Iba 1 for overnight at $4^{\circ} \mathrm{C}$. Besides, the slides were counterstained with thioflavin $\mathrm{S}$ and 6-diamino-2-phenylindole (DAPI; Thermo Fisher Scientific). The fluorescence signals were detected by Zeiss LSM710 confocal microscope.

\section{Optimization of key parameters}

To keep the dLFI with the optical working condition, we detail to optimize the volume of $\mathrm{K}_{2} \mathrm{CO}_{3}$ and the $\mathrm{mAb}$ $1 \mathrm{~F} 12$ concentration of conjugation. For the volume of $\mathrm{K}_{2} \mathrm{CO}_{3}$ optimization, the $1 \mathrm{~mL}$ of the AuNP solution was adjusted to $4,8,12,16,20,24,28$, and $32 \mu \mathrm{L}$ of $0.1 \mathrm{M}$ $\mathrm{K}_{2} \mathrm{CO}_{3}$. While for mAb 1F12 concentration optimization, the mAb $1 \mathrm{~F} 12$ was added dropwise to $1 \mathrm{~mL}$ of AuNP solution at final concentrations of $5,10,15,20,25$, and $30 \mu \mathrm{g} / \mathrm{mL}$.

\section{Preparation of dLFI}

Scheme $1 \mathrm{~b}$ describes the main components of a onepiece dLFI, which mainly includes sample pads, conjugation pads, signal pads, and absorbent pads assembled on a plastic backplane in sequence. The sample pad was impregnated with a buffer solution (0.01 M PBS, pH 7.4, including 1\% BSA, 2\% Sucrose, 0.1\% PEG, and 0.05\% Tween-20) and air-dried overnight before use. The goat anti-mouse IgG antibody, 1F12, and 2C6 were coated on the NC membrane to form a control line and two test lines. The coated NC membrane was dried for $30 \mathrm{~min}$ and blocked with $1 \%(\mathrm{w} / \mathrm{v})$ BSA dissolved in $0.01 \mathrm{M}$ PBS for $2 \mathrm{~h}$ at $25^{\circ} \mathrm{C}$. After blocking, the membrane was washed 
three times with PBS containing 0.05\% [v/v] Tween-20 (PBS-T) and dried at $25^{\circ} \mathrm{C}$. Following this, the dLFI was assembled in the following order: the sample pad was first placed on the PVC plate, overlapping the anti-A $\beta_{42}$ $\mathrm{mAb} 1 \mathrm{~F} 12$ conjugate pad by $2 \mathrm{~mm}$, and the bottom of the antibody-coated NC membrane was then overlapped by $2 \mathrm{~mm}$. Next, the absorbent pad was overlapped on the top of the NC membrane by $2 \mathrm{~mm}$. After assembly, the plate was evenly cut into $3.5 \mathrm{~mm}$ wide strips, sealed with a desiccant, and stored at $25^{\circ} \mathrm{C}$. The concentration of $1 F 12$ coated on the first test line and 2C6 coated on the second test line was $1 \mathrm{mg} / \mathrm{mL}$. The concentration of goat anti-mouse IgG antibody coated on the control line was $0.5 \mathrm{mg} / \mathrm{mL}$.

\section{Detection principle and test procedure of dLFI}

Our multicomponent biosensor system developed for rapidly and simultaneously detecting $\mathrm{A} \beta_{42} \mathrm{Ms}$ and $\mathrm{A} \beta_{42}$ Os was based on two groups of paired mAbs. Due to $\mathrm{A} \beta_{42} \mathrm{Os}$ was aggregated by several $\mathrm{A} \beta_{42} \mathrm{Ms}$, we used the group of 1 F12/1F12 with the same epitope that ensures only $A \beta_{42}$ Os was detected but not $A \beta_{42} \mathrm{Ms}$, which need a pair of antibodies with different epitopes just liking our described as the group of $1 \mathrm{~F} 12 / 2 \mathrm{C} 6$. The following steps were included in dLFI assay process: the antibody-modified MNPs were used for the enrichment of $A \beta$ peptides dissolved in the samples and then eluted with $0.1 \mathrm{M}$ glycine ( $\mathrm{pH} 3.0)$, followed by immediate neutralization to $\mathrm{pH} 7.4$ using a neutralization buffer $(1 \mathrm{M}$ Tris- $\mathrm{HCl}, \mathrm{pH}$ 8.5). Each collected solution (approximately $50 \mu \mathrm{L}$ ) was dripped onto the sample pad. $\mathrm{A} \beta_{42} \mathrm{Ms}$ and/or $\mathrm{A} \beta_{42} \mathrm{Os}$ in samples were first recognized by $1 \mathrm{~F} 12-\mathrm{AuNP}$ conjugate mixture on the conjugate pad and migrated along the $\mathrm{NC}$ membrane via capillary action. The $\mathrm{A} \beta_{42} \mathrm{Os}-1 \mathrm{~F} 12-$ AuNP complex was first solubilized by 1 F12 coated on the NC membrane to form the test line 1, whereas $\mathrm{A} \beta_{42} \mathrm{Ms}-1 \mathrm{~F} 12-\mathrm{AuNP}$ complex continued to migrate until it was solubilized by mAb $2 \mathrm{C} 6$ coated on the $\mathrm{NC}$ membrane to form the test line 2. The remaining 1F12AuNP were captured by goat anti-mouse IgG coated on the NC membrane to form the control line. The test results were evaluated within $5 \mathrm{~min}$.

\section{Preparations of oligomeric and monomeric $A \beta$}

The detailed steps of oligomeric and monomeric $A \beta$ preparations were described in our previous report [51]. In brief, $A \beta_{42}$ Ms and $A \beta_{40}$ Ms were obtained by dissolving lyophilized $A \beta_{42}$ or $A \beta_{40}$ peptides in 1,1,1,3,3,3-hexafluoroisopropanol (HFIP) for overnight incubation at $25^{\circ} \mathrm{C}$. HFIP was evaporated with nitrogen to form a thin film, and $A \beta$ was re-dissolved in dimethyl sulfoxide. $A \beta_{42}$ oligomers $\left(A \beta_{42} \mathrm{Os}\right)$ and $A \beta_{40}$ oligomers $\left(A \beta_{40} \mathrm{Os}\right)$ were obtained from $50 \mu \mathrm{MA} \beta_{42}$ or $A \beta_{40}$ monomer solution after $24 \mathrm{~h}$ incubation at $37^{\circ} \mathrm{C}$ in the dark, respectively.

\section{Specificity and sensitivity of the dLFI}

Several different compounds such as $A \beta_{40} \mathrm{Ms}, \mathrm{A} \beta_{40} \mathrm{Os}$, p-Tau ${ }^{396,404}$, Cis-Tau, p-Tau ${ }^{231}$, and BSA were detected to evaluate the specificity of the dLFI. For sensitivity evaluation, a series of synthetic $A \beta_{42} \mathrm{Ms}$ and $\mathrm{A} \beta_{42} \mathrm{Os}$ dilutions, ranging from $625 \mathrm{ng} / \mathrm{mL}$ to $154 \mathrm{pg} / \mathrm{mL}$, were prepared by diluting with PBS. Each dilution was applied to the dLFI test, and the detection limit was determined. The visual limit of detection is defined as the minimum concentration of $A \beta_{42} \mathrm{Ms}$ and $A \beta_{42}$ Os that leads to the complete disappearance of the test line.

\section{Analysis of blood samples using dLFI}

All procedures involving animal studies have been reviewed and approved by the Institutional Animal Care and Use Committee of Huazhong University of Science and Technology. Human blood samples were obtained from the patients/participants in Union Hospital of Huazhong University of Science and Technology who have been provided with their written informed consent to participate in this study.

The blood samples of 5xFAD mice (Stock No: 34848JAX) aged 3 months $(n=4)$ and 9 months $(n=4)$ were collected and used to evaluate the analytical performance and applicability of the dLFI. A mixture of $A \beta_{42} \mathrm{Ms}$ and $A \beta_{42}$ Os was used as a positive control, while blood samples from C57BL/6 J mice at 3 months $(n=3)$ and 9 months old $(n=3)$ were used as negative controls. In addition, blood samples collected from $\mathrm{HC}(\mathrm{n}=7)$ and AD patients $(n=8)$ were analyzed with dLFI. The detailed information of the participant in this manuscript is summarized in Additional file 1: Table S1.

\section{Validation and analysis with sandwich ELISA}

The blood samples of $5 \mathrm{xFAD}$ or $\mathrm{C} 57 \mathrm{BL} / 6 \mathrm{~J}$ mice at 3 months $(n=4)$ and 9 months of age $(n=4)$, and HC $(n=7)$ and AD patients $(n=8)$ were analyzed via a prepared sandwich ELISA for $A \beta_{42}$ monomers and $A \beta_{42}$ oligomers as our previous described [51].

\section{Statistical analyses}

The data are presented as means $\pm \mathrm{SD}$. Unpaired $t$-test was used for two-group comparisons. One-way analysis of variance (ANOVA) was used for multigroup comparisons. Statistical significance is represented in the figure by "p $<0.05,{ }^{* * *} \mathrm{p}<0.01,{ }^{* * * *} \mathrm{p}<0.001$, ${ }^{* * * * *} \mathrm{p}<0.0001$, and n.s. (indicating no significance). All statistical analyses were performed with GraphPad Prism 8.0 software. 


\section{Results and discussion}

\section{Mechanism of the proposed biosensor}

In this study, we combined the biomarker measurement of $A \beta_{42} \mathrm{Ms}$ and $A \beta_{42}$ Os to obtain a more accurate diagnosis of AD. To further verify the results, we developed dLFI using two matched antibody pairs 1F12/1F12 and 1F12/2C6 to obtain a rapid on-site response and accurate detection tests and to determine the changes of $A \beta_{42} \mathrm{Ms}$ and $A \beta_{42}$ Os in the blood for clinical validation of AD diagnosis. As shown in Scheme 1a, the blood samples were firstly enriched with MNPs modified by $\mathrm{mAb} 1 \mathrm{~F} 12$, and then the $A \beta_{42} \mathrm{Ms}$ or/and $\mathrm{A} \beta_{42} \mathrm{Os}$ were eluted for LFI analysis. The eluted $A \beta_{42} \mathrm{Ms}$ or $\mathrm{A} \beta_{42}$ Os were added to the sample pad and then recognized by the 1F12-AuNP conjugate mixture on the conjugate pad and migrated along the NC membrane via capillary action. The $\mathrm{A} \beta_{42} \mathrm{Os}-1 \mathrm{~F} 12-\mathrm{AuNP}$ complex was first fixed by $1 \mathrm{~F} 12$ coated on the $\mathrm{NC}$ membrane to form the test line 1 , due to $A \beta_{42}$ Os were aggregated by multiple monomers, exposing several same epitopes that could be recognized by the same detection antibody (Scheme 1b). This strategy is only used for the detection of $A \beta_{42} \mathrm{Os}$. The $\mathrm{A} \beta_{42} \mathrm{Ms}-1 \mathrm{~F} 12-\mathrm{AuNP}$ complex continued to migrate and was solubilized by mAb $2 \mathrm{C} 6$ with different epitopes toward $A \beta_{42}$ (specific to amino acids 3-9, 13-19, 18-25, 29-36, and $36-42$ of $A \beta_{42}$ sequence). Compared to 1 F12 (specific to amino acids $3-9$ ), $A \beta_{42}$ Ms were only detected by a pair of antibodies with different epitopes (Scheme 1c). If $A \beta_{42} \mathrm{Ms}$ and $\mathrm{A} \beta_{42} \mathrm{Os}$ are present in the sample, the 1F12-AuNP conjugates will be combined with the two test lines and the control line (Scheme 1d). If there is no $A \beta_{42}$ in the sample solution, the 1F12-AuNP conjugates will not bind to the two test lines but will show the control line, forming a red band (Scheme 1e).

\section{Characterization of $\mathrm{mAb} 1 \mathrm{~F} 12$ and $2 \mathrm{C} 6$}

We first evaluated whether the two antibodies could stain $\mathrm{A} \beta$ plaques in the brains of $5 \mathrm{xFAD}$ mice. The results of confocal fluorescence images showed that $A \beta$ plaques were stained by Cy3-labeled 1 F12 or $2 \mathrm{C} 6$ and co-localized with thioflavin $S$, and its functional characteristic was to bind $A \beta$ plaques (Fig. 1a) [54-56]. The binding selectivities of $1 \mathrm{~F} 12$ and $2 \mathrm{C} 6$ for different $\mathrm{A} \beta$ species were detected by competitive ELISA. The morphology of the prepared $A \beta_{42} \mathrm{Ms}$ and $\mathrm{A} \beta_{42} \mathrm{Os}$ was first confirmed by TEM. The results showed that the morphology of $\mathrm{A} \beta_{42} \mathrm{Ms}$ was coil structures (Fig. 1b, left), while $\mathrm{A} \beta_{42} \mathrm{Os}$ presented a $\beta$-sheet and typical fibril structure (Fig. 1b, right). A $12 \%$ reduced SDS-PAGE gel was used to confirm the molecular weight and components of the prepared $A \beta_{42}$ Ms and $A \beta_{42}$ Os (Fig. 1c). Western blot results showed that both $\mathrm{A} \beta_{42} \mathrm{Ms}$ and $\mathrm{A} \beta_{42}$ Os were well recognized by 1 F12 or 2 C6 (Fig. 1d). Competitive ELISA was used to evaluate the binding selectivity of $1 \mathrm{~F} 12$ and $2 \mathrm{C} 6$ to different $A \beta$ species. Figures $1 \mathrm{e}$ and $\mathrm{f}$ show that $1 \mathrm{~F} 12$ and $2 \mathrm{C} 6$ have high binding selectivity to $A \beta_{42}$ species rather than $A \beta_{40}$. The IC50 values of $1 F 12$ for $A \beta_{42}$ Ms and $A \beta_{42} \mathrm{Os}$ were $180.8 \mathrm{nM}$ and $18.1 \mathrm{nM}$, respectively. While for $2 \mathrm{C} 6$, the IC50 values for $A \beta_{42} \mathrm{Ms}$ and $\mathrm{A} \beta_{42} \mathrm{Os}$ were $90.3 \mathrm{nM}$ and $7.5 \mathrm{nM}$, respectively (Fig. 1g). The IC50 values plus the $\mathrm{K}_{\mathrm{d}}$ values of $1 \mathrm{~F} 12\left(\mathrm{~K}_{\mathrm{d}}=1.66 \pm 0.09 \mathrm{nM}\right.$ for $\mathrm{A} \beta_{42} \mathrm{Ms}$ and $K_{d}=0.38 \pm 0.04 \mathrm{nM}$ for $\mathrm{A} \beta_{42} \mathrm{Os}$ ) and $2 \mathrm{C} 6$ $\left(K_{d}=3.59 \pm 0.27 \mathrm{nM}\right.$ for $\mathrm{A} \beta_{42} \mathrm{Ms}$ and $K_{d}=0.61 \pm 0.03 \mathrm{nM}$ for $\mathrm{A} \beta_{42} \mathrm{Os}$ ) that were reported in our previous study indicated [51] that 1F12 and 2C6 have high binding affinity and selectivity for both $\mathrm{A} \beta_{42} \mathrm{Ms}$ and $\mathrm{A} \beta_{42} \mathrm{Os}$.

\section{Characterization of AuNP and AuNP-1F12 conjugates}

The synthesized AuNP had good dispersion and uniformity with wine red, and a characteristic single absorption peak was found at $525 \mathrm{~nm}$ (Additional file 1: Fig. S4a). The morphology and size of prepared AuNP were characterized using a Tecnai G20 transmission electron microscope and dynamic light scattering with an average size of $40 \mathrm{~nm}$ (FEI Ltd., USA) (Fig. 2a and b). After being conjugated with $1 \mathrm{~F} 12$, the size distribution and $\zeta$-potential of AuNP-1F12 increased significantly with the size from $40 \mathrm{~nm}$ (before conjugation) to approximately $80 \mathrm{~nm}$ (after conjugation) (Fig. 2b) and $\zeta$-potential from - 38 (before conjugation) to approximately -23 (after conjugation) (Additional file 1: Fig. S4b). Besides, the absorption spectrum of 1F12 was measured, and the results showed a sharp decrease in the absorption peak at $280 \mathrm{~nm}$ after conjugation with AuNP (Additional file 1: Fig. S4c). Coupled with the results of the $12 \%$ reduction SDS-PAGE gel, they jointly confirmed the successful combination of $1 F 12$ to AuNP (Fig. 2c). The ELISA was used to evaluate the bioactivity of AuNP-1F12 conjugate and results showed that both 1F12 and AuNP-1F12 reacted well with $A \beta_{42}$ (Fig. 2d).

\section{Optimization of the dLFI}

To improve the sensitivity, accuracy, and reproducibility of the dLFI test, the capture antibody 1F12-AuNP was optimized during the preparation process. We first optimized the volume of $\mathrm{K}_{2} \mathrm{CO}_{3}$, which is a commonly used buffer to adjust the $\mathrm{pH}$ of AuNPs solution to better bind the antibody. Figure $2 \mathrm{e}$ and g show the effect of $\mathrm{K}_{2} \mathrm{CO}_{3}$ volume on the 1F12-AuNP conjugates. As the volume of $\mathrm{K}_{2} \mathrm{CO}_{3}$ increased from 4 to $16 \mu \mathrm{L}$, the color, optical density (OD) value, and absorption spectrum at $525 \mathrm{~nm}$ of the 1F12-AuNP solution gradually increased, the color of the solution changed from lavender to wine red (Fig. 2e), and the $\mathrm{OD}_{525}$ value increased from 0.23 to 0.71 (Fig. 2g). With a further increase from 20 to $32 \mu \mathrm{L}$, the $\mathrm{OD}_{525}$ value (Fig. $2 \mathrm{~g}$ ) and the 


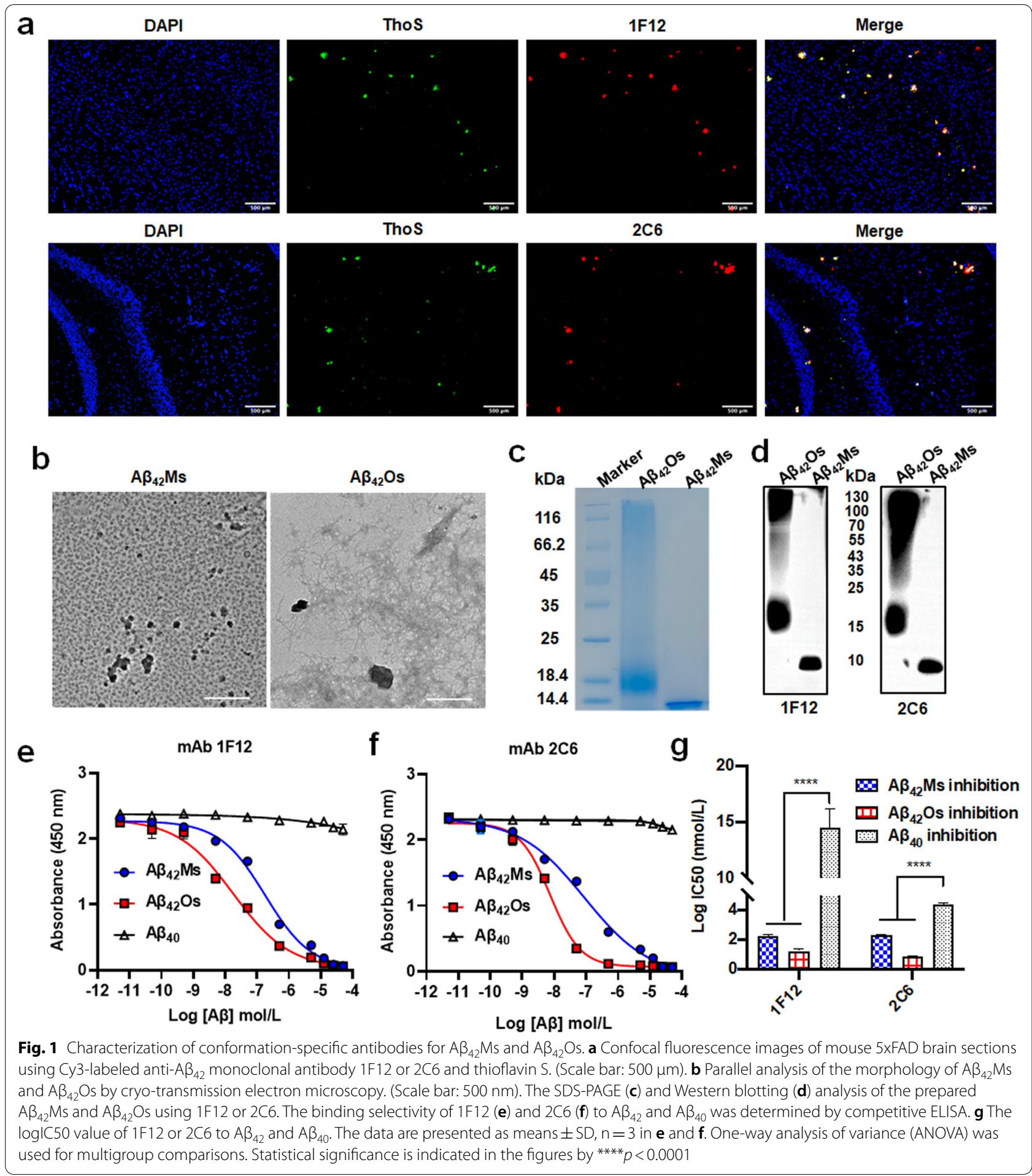

absorption spectrum (Fig. S4d) decreased slightly. To obtain a higher colorimetric ratio, $16 \mu \mathrm{L}$ was selected as the optimal volume of $\mathrm{K}_{2} \mathrm{CO}_{3}$ of antibody coupling, and the $\mathrm{pH}$ value of the AuNPs solution was approximately 8.5. When the $\mathrm{pH}$ value is equal to or slightly high than the isoelectric point $(\mathrm{pI})$ of the antibody $(\mathrm{pI}=8)$, the antibody is electrically neutral, resulting in a small electrostatic interaction between the antibody and AuNPs, so that the antibody is more easily to adsorb on the surface of AuNPs [57-59]. When the pH value is less 

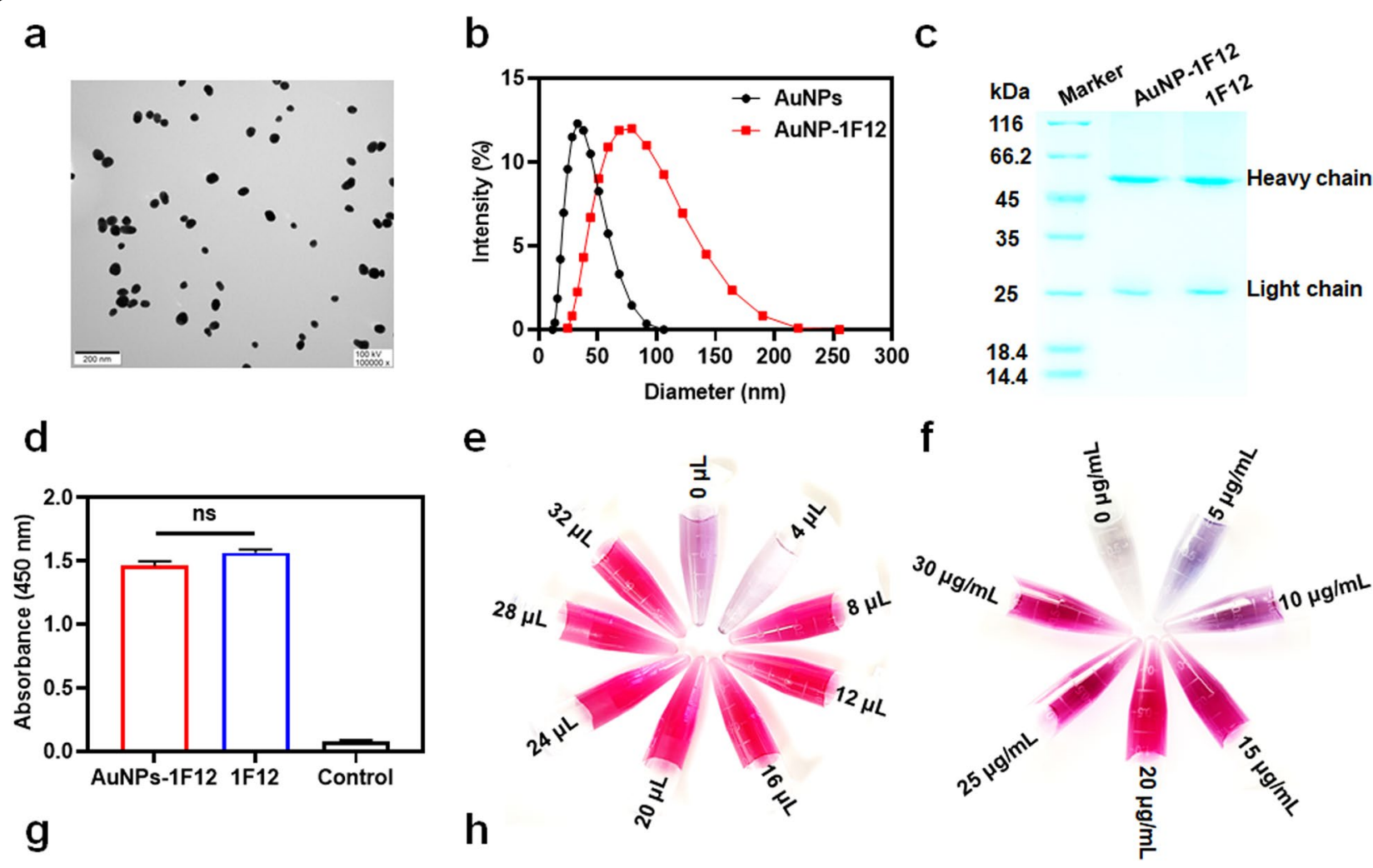

e
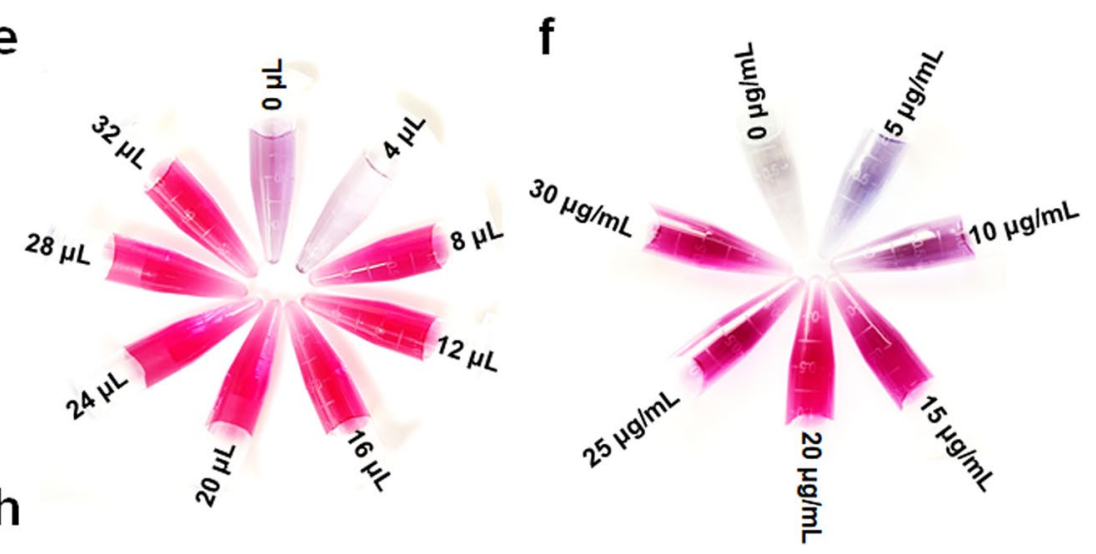
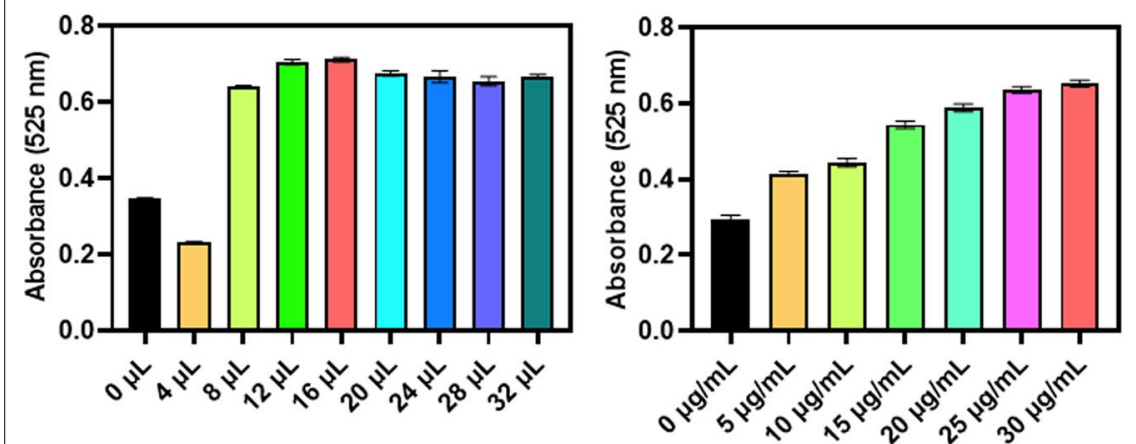

Fig. 2 Characterization of AuNP-1F12 conjugates. a TEM images of synthetic AuNP. (Scale bar: 200 nm). b The size distributions of AuNP before and after modification. c A 12\% reduced SDS-PAGE gel analysis of AuNP-1F12 and 1F12. d ELISA was used to determine the bioactivity of AuNP-1F12 conjugates. The optimal volume of $\mathrm{K}_{2} \mathrm{CO}_{3}$ for the conjugation of $1 \mathrm{~F} 12$ with AuNP was evaluated by the color $(\mathbf{e})$ and $\mathrm{OD}_{525}$ value $(\mathbf{g})$. The color $(\mathbf{f})$ and $\mathrm{OD}_{525}$ value (h) were used to evaluate the optimal concentration of 1 F12 of synthetic AuNP-1F12. For Fig. 3b, d, g, and h, the data are presented as mean $\pm S D, n=3$. Statistical significance is indicated in the figures by n.s. (indicating no significance)

than the pI, the antibody is positively charged. Since the AuNP is negatively charged, the antibody is easily adsorbed to form large polymers, leading to the aggregation of AuNPs [57-59]. On the contrary, once the $\mathrm{pH}$ is higher than the $\mathrm{pI}$, the antibody will be negatively charged and repel the negatively charged AuNPs, causing them to fail to bind to each other [57-59].

As shown in Fig. $2 \mathrm{f}$ and $\mathrm{h}$, as the concentration of $1 \mathrm{~F} 12$ increases from 5 to $25 \mu \mathrm{g} / \mathrm{mL}$, the color gradually changes from purple to wine red (Fig. 2f), and the $\mathrm{OD}_{525}$ value (Fig. 2h) increases from 0.41 to 0.64 . However, when the concentration of 1F12 was as high as $30 \mu \mathrm{g} /$ $\mathrm{mL}$, the $\mathrm{OD}_{525}$ value (Fig. $2 \mathrm{~h}$ ) and absorption spectrum (Additional file 1: Fig. S4e) only slightly increased. Therefore, the optimal concentration of $1 \mathrm{~F} 12$ was $25 \mu \mathrm{g} / \mathrm{mL}$. The significant change in the color of the AuNP solution during the antibody coupling process could be explained by the fact that the AuNPs cannot be fully labeled when no antibody is added or the amount of added antibody is insufficient. The unlabeled AuNPs were aggregated under 


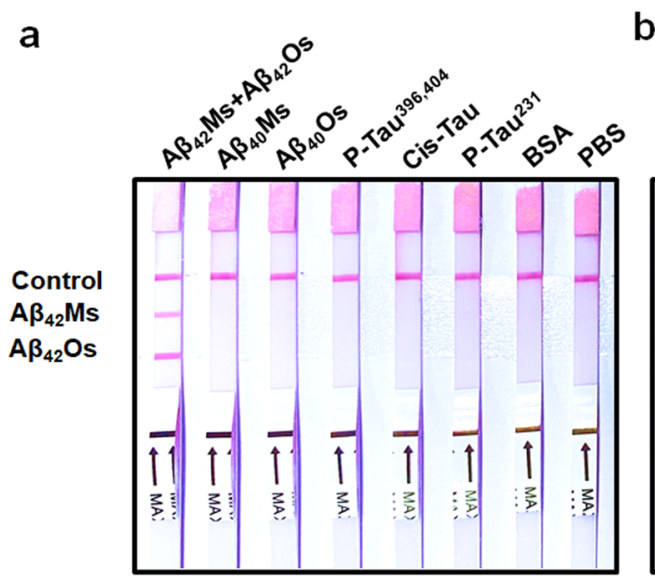

b

C
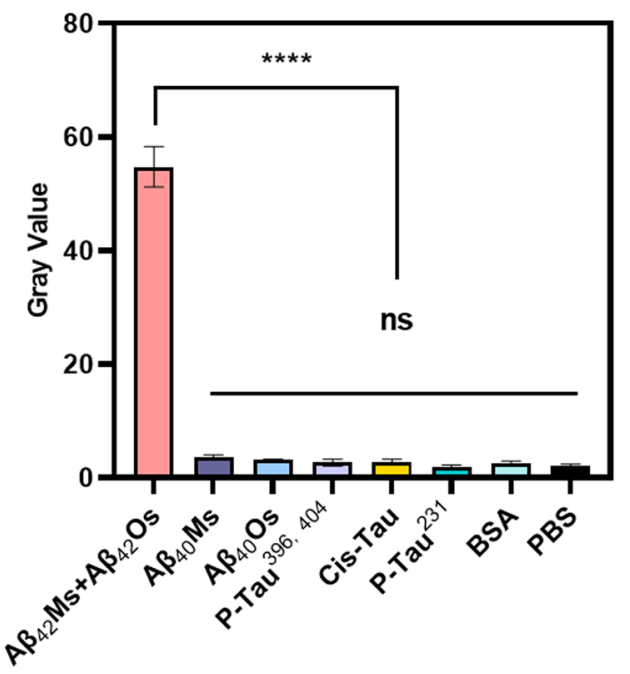

e

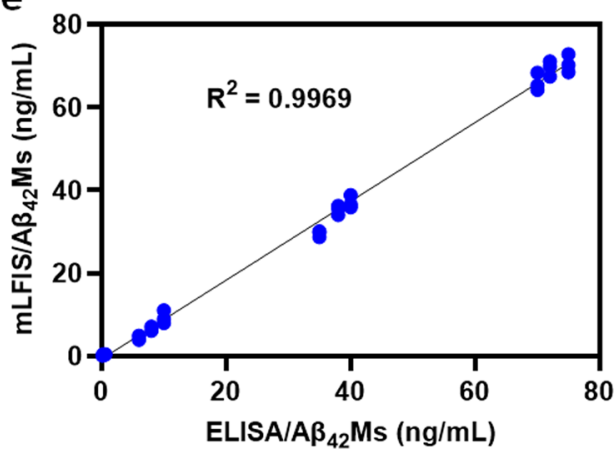

d

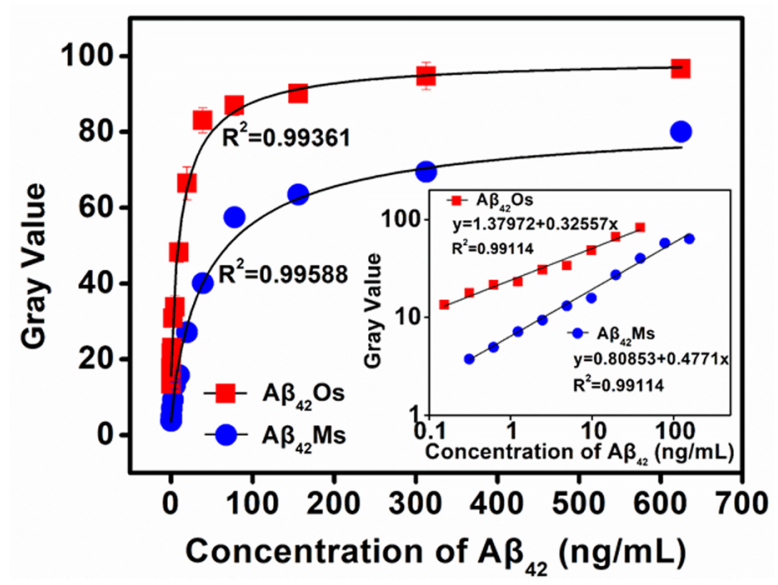

f

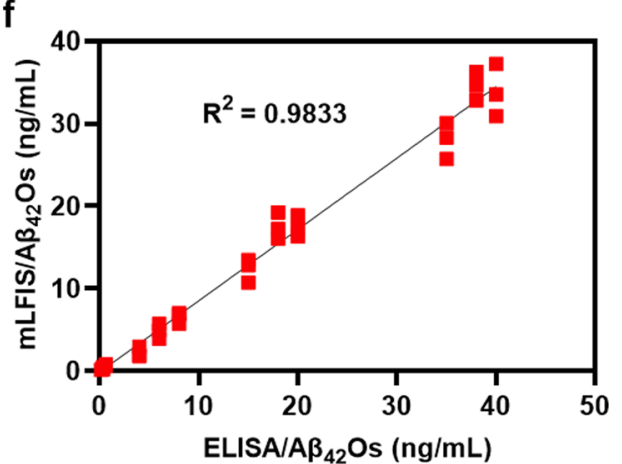

Fig. 3 The performance of the dLFI. The visual result ( $\mathbf{a})$ and gray value (c) on the $T$ line of the dLFI in the specificity assay, $n=3$. $\mathbf{b}$ The sensitivity of $\mathrm{dLFI}$ for the simultaneous detection of $A \beta_{42} \mathrm{Ms}$ and $A \beta_{42} \mathrm{Os}$. $\mathbf{d}$ The plotted linear curve of different $A \beta_{42}$ conformations, $n=3$. e, $\mathbf{f}$ Correlation between results from dLFI (Y-axis) and sandwich ELISA (X-axis) in spiked samples, $n=12$. Data are presented as means \pm SD. One-way analysis of variance (ANOVA) was used for multigroup comparisons. Statistical significance is represented in the figures by ${ }^{* * * *} p<0.0001$ and $n . s$. (indicating no significance)

the action of $10 \% \mathrm{NaCl}$. On the contrary, only when the amount of antibody reaches or slightly exceeds the stable amount, the AuNPs can remain stable [60, 61].

\section{Specificity and sensitivity of the dLFI}

The specificity of dLFI was evaluated among six compounds. As shown in Fig. 3a, dLFI can detect a mixture of $\mathrm{A} \beta_{42} \mathrm{Ms}$ and $\mathrm{A} \beta_{42} \mathrm{Os}$, and does not cross-react with the 
a

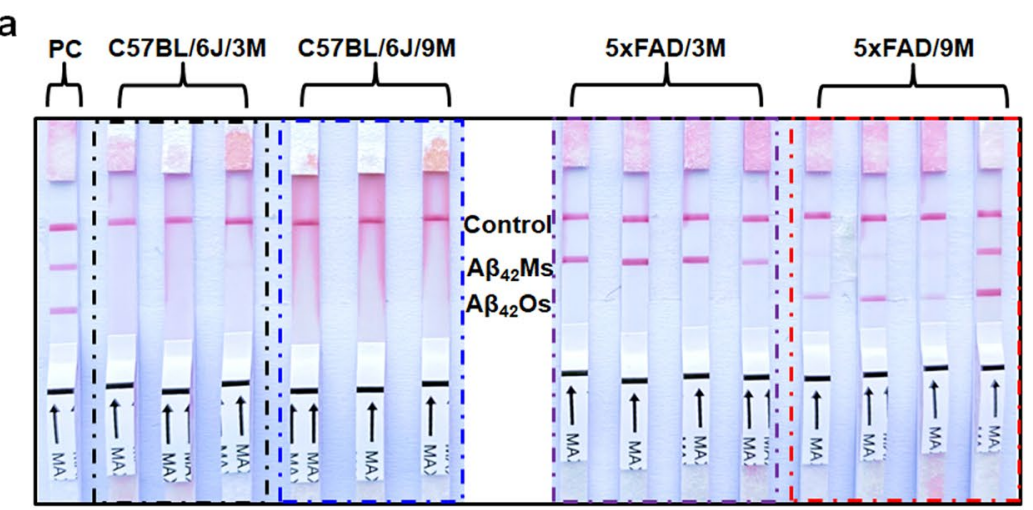

b

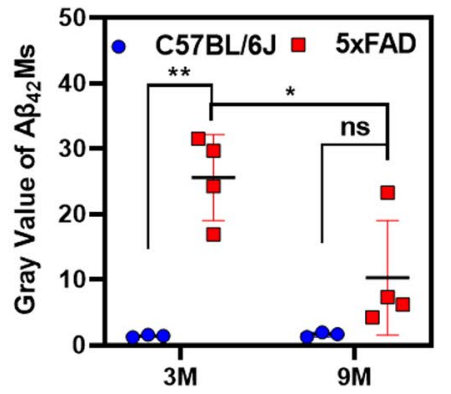

C

d
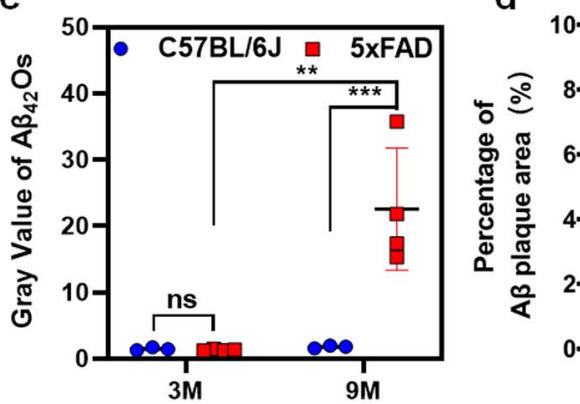

e

f

DAPI
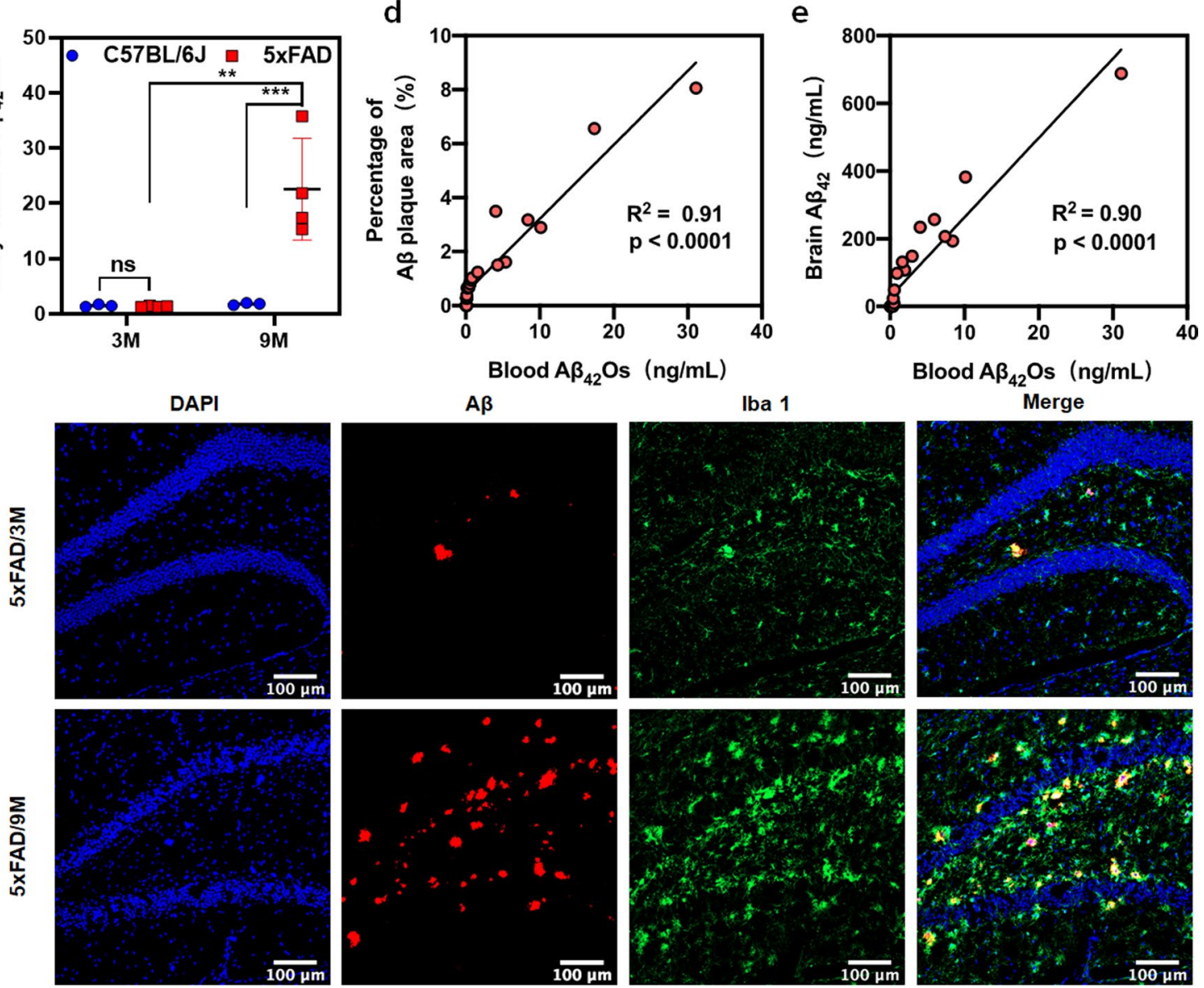

Fig. 4 Simultaneous detection of $A \beta_{42} M s$ and $A \beta_{42} O s$ in the blood of 3- and 9-month-old 5xFAD and C57BL/6 J mice. The visual results (a) and grey value $(\mathbf{b}, \mathbf{c})$ on the T-line of the dLFI in blood samples from 5 XFAD $(n=8)$ and C57BL/6 J $(n=6)$ mice at 3 and 9 months old. $\mathbf{d}$, e Correlation between blood $A \beta_{42}$ Os level and $A \beta$ plaque area $(\mathbf{d}, p<0.0001)$ or soluble $A \beta_{42}$ level $(\mathbf{e}, p<0.0001)$ in the brain of $5 \times F A D$ mice, a total of $n=25$, of which $n=5$ in each age group, including 1,3,6, 9, and 12 months old. $\mathbf{f}$ Confocal fluorescence images of A $\beta$ plaques and Iba 1-positive cell staining in 3 or 9-month-old 5xFAD mice. (Scale bar: $100 \mu \mathrm{m}$ ). Data are presented as means \pm SD. Unpaired $t$-test was used for two-group comparisons. Statistical significance is indicated in the figures by ${ }^{* *} p<0.01,{ }^{* * *} p<0.001$ and n.s. (indicating no significance)

tested peptides, indicating that dLFI based on $1 \mathrm{~F} 12 / 1 \mathrm{~F} 12$ and 1F12/2C6 antibody pairs could accurately detect both $A \beta_{42}$ Os and $A \beta_{42}$ Ms (Fig. 3a and c). Therefore, dLFI can be used to effectively evaluate multiple analytes. Each test line in the strip has a cut-off value, which is the minimum $\mathrm{A} \beta_{42} \mathrm{Ms}$ or $\mathrm{A} \beta_{42}$ Os concentration required to make the test line visible in samples. For $A \beta_{42} \mathrm{Ms}$ or $\mathrm{A} \beta_{42} \mathrm{Os}$, the cut-off value of the dLFI was $154 \mathrm{pg} / \mathrm{mL}$ (Fig. $3 \mathrm{~b}$ ). 


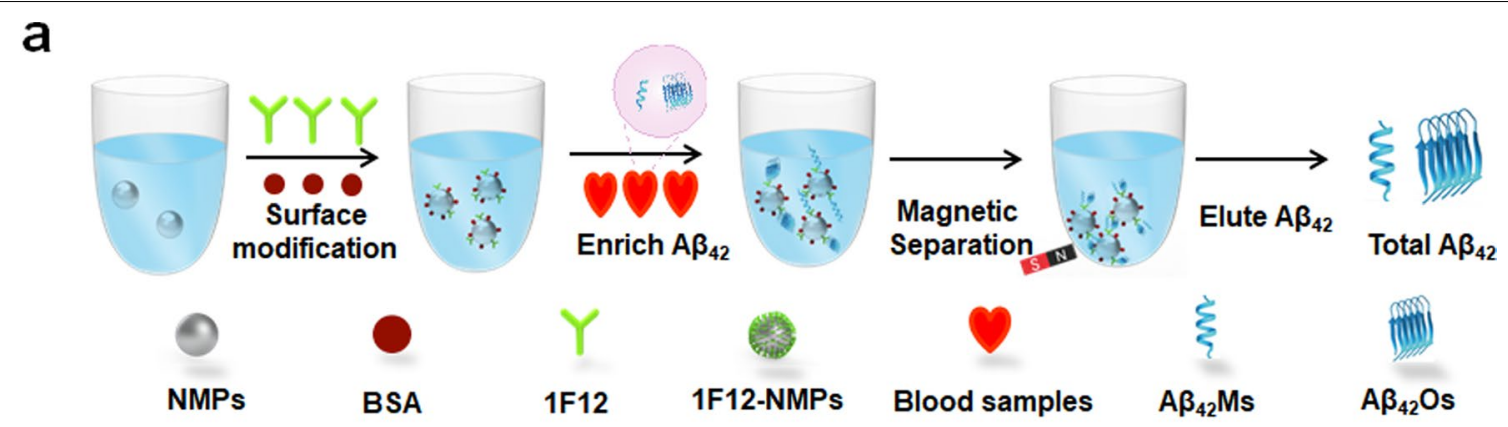

b

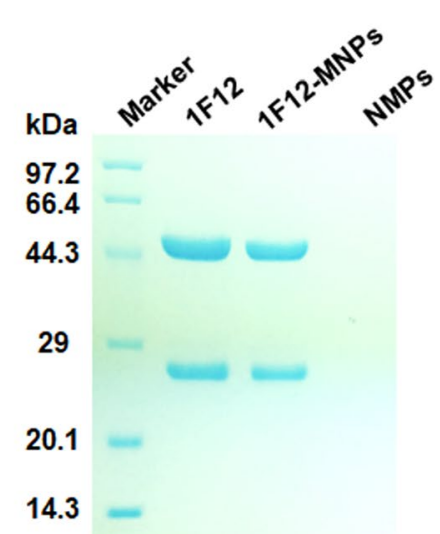

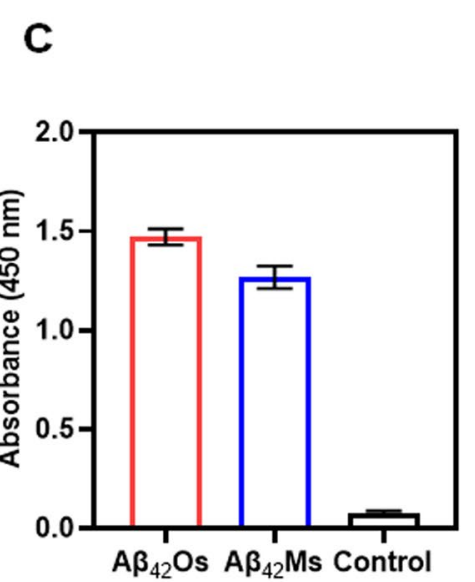

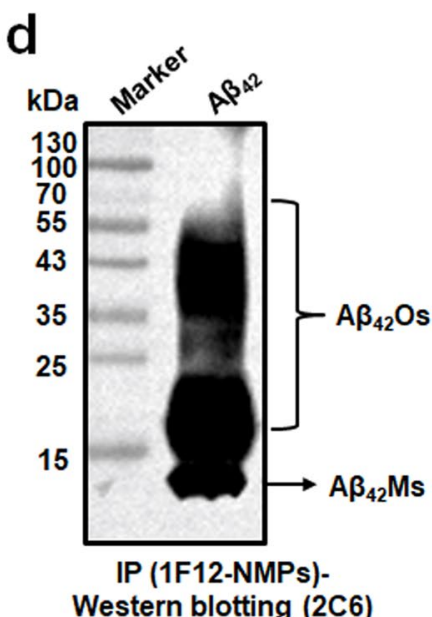

Western blotting (2C6)

Fig. 5 Characterization of antibody-modified NHS-magnetic nanoparticles (MNPs). a Schematic illustration of the working steps for the use of antibody-modified MNPs for the enrichment of $\mathrm{A} \beta_{42} \mathrm{Os}$ and/or $\mathrm{A} \beta_{42} \mathrm{Ms}$. b A 12\% reduced SDS-PAGE gel analysis of 1F12-MNPs. $1 \mathrm{~F} 12$ and NMNs were used as controls. ELISA (c) and IP-Western blotting (d) analysis for the bioactivity of 1F12-MNPs. Data are presented as means $\pm S D, n=3$ in $\mathbf{c}$

Different concentrations of $\mathrm{A} \beta_{42} \mathrm{Ms}$ and $\mathrm{A} \beta_{42} \mathrm{Os}$ were used in dLFI to generate two standard curves. The color intensity of the test line is directly proportional to the concentration of the analyte in samples. Figure $3 \mathrm{~d}$ shows two standard curves of dLFI. The linear relationship of $\mathrm{dLFI}$ is $\mathrm{y}=1.37972+0.32557 \mathrm{x}$, and the LOD of $\mathrm{A} \beta_{42} \mathrm{Os}$ is $154 \mathrm{pg} / \mathrm{mL}$ (Fig. 3d, inserted Figure, red square). The linear relationship of dLFI is $y=0.80853+0.4771 \times$ with LOD of $154 \mathrm{pg} / \mathrm{mL}$ for $\mathrm{A} \beta_{42} \mathrm{Ms}$ (Fig. 3d, inserted Figure, blue circle).

\section{The reliability and practicability of the proposed dLFI}

The reliability and practicability of the proposed dLFI sensor in spiked samples were verified and compared by sandwich ELISA. The spiked concentration conformed to the linear range. Therefore, the results (Fig. 3e and f) showed that the two methods were well consistent. The correlation coefficients of $\mathrm{A} \beta_{42} \mathrm{Ms}$ and $\mathrm{A} \beta_{42} \mathrm{Os}$ were 0.9969 and 0.9833 , respectively. Although the sensitivity of dLFI is relatively low, the dLFI sensor requires less than 30 min of enrichment and immunoreaction time to complete sample analysis, while traditional sandwich ELISA requires about $3 \mathrm{~h}$.

\section{The performance of the dLFI in detecting $A \beta_{42} \mathrm{Os}$ and $A \beta_{42} \mathrm{Ms}$ in $5 \times \mathrm{XAD}$ mice}

To check the performance of the dLFI in the actual tests, blood samples of 5xFAD (AD model mice) or C57BL/6 J mice (control mice) at 3 and 9 months old were collected for dLFI detection. The mixture of $A \beta_{42} \mathrm{Ms}$ and $\mathrm{A} \beta_{42} \mathrm{Os}$ was used as a positive control. The results showed that in the blood of C57BL/6 J mice at 3 and 9 months old, dLFI could hardly detect $A \beta_{42} \mathrm{Ms}$ or $\mathrm{A} \beta_{42} \mathrm{Os}$ (Fig. 4a, left, black and blue box, and Fig. $4 \mathrm{~b}-\mathrm{c}$ ). Interestingly, the dLFI results showed that $A \beta_{42}$ Ms were the main form of $A \beta_{42}$ in 3-month-old 5xFAD mice (Fig. 4a, right, purple box, and Fig. 4b), but the results were different in 9-monthold 5xFAD mice. In 9-month-old 5xFAD mice, the color of $\mathrm{A} \beta_{42} \mathrm{Os}$ in the first test line was significantly enhanced, but $\mathrm{A} \beta_{42}$ Ms were hardly observed in three of the four 5xFAD mice (Fig. 4a, right, red box, and Fig. 4c). Only one of the four 9-month-old 5xFAD mice showed high levels of $A \beta_{42}$ Ms and $A \beta_{42}$ Os. These results revealed that 

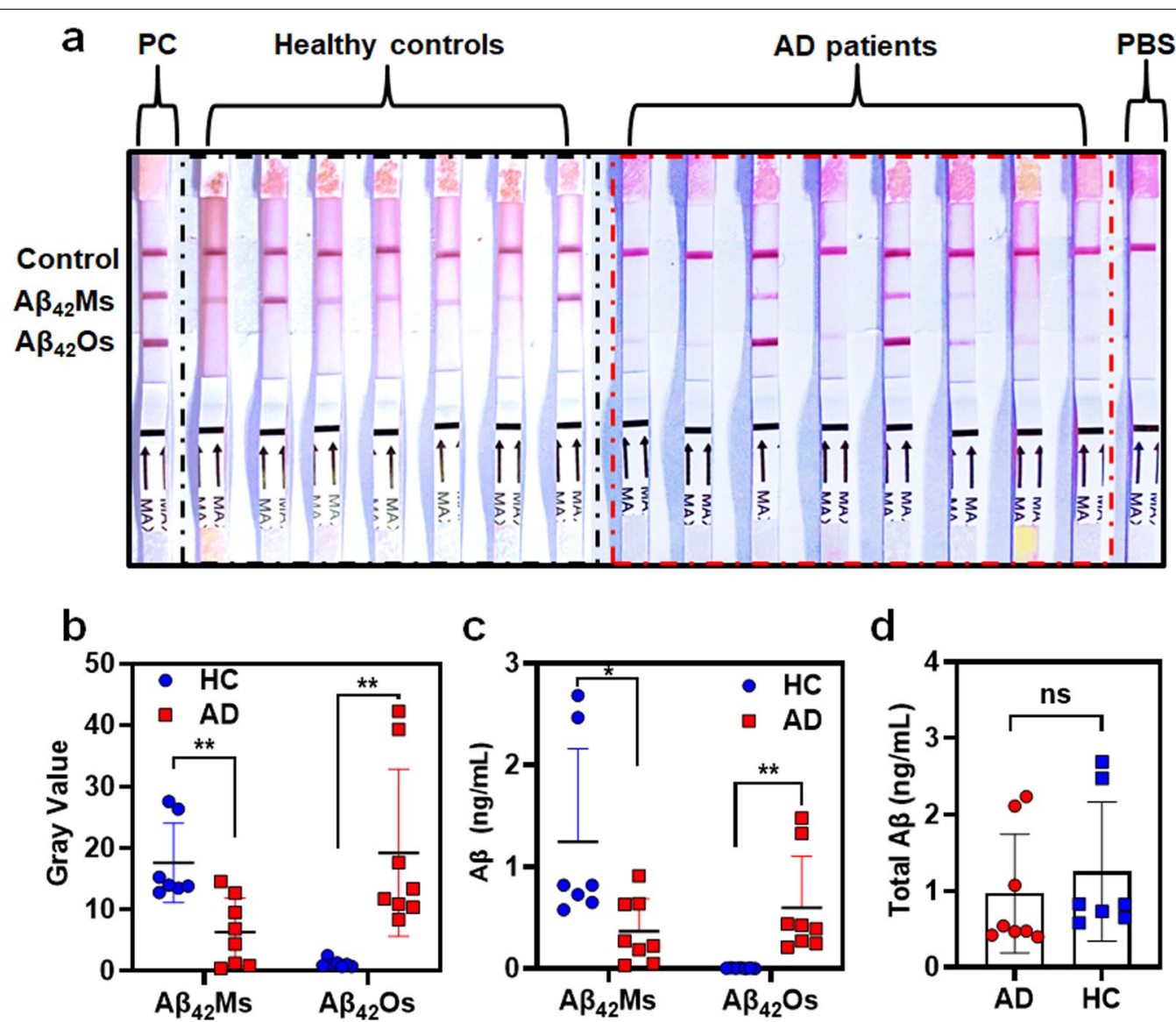

Fig. 6 Detection of $A \beta_{42} M s$ and/or $A \beta_{42} O$ s in human blood samples by dLFl. The visual results (a) and grey value $(\mathbf{b})$ of the $A \beta_{42} M s$ and/or $A \beta_{42} O$ s level in the blood of $A D$ patients $(n=8)$ or healthy controls $(n=7)$ were analyzed by dLFl. $\mathbf{c}$ The $A \beta_{42} M s$ and/or $A \beta_{42} O s$ levels in the blood of AD patients $(n=8)$ or healthy controls $(n=7)$ were detected by sandwich ELISA. $\mathbf{d}$ Total $A \beta_{42}$ levels in human blood samples were detected by sandwich ELISA ( $n=8$ for AD patients and $n=7$ for healthy controls). Data are presented as means $\pm S D$. Unpaired $t$-test was used for two-group comparisons. Statistical significance is indicated in the figures by ${ }^{*} p<0.05,{ }^{* *} p<0.01$ and n.s. (indicating no significance)

Table 1 Performance appraisals among A analytical techniques

\begin{tabular}{|c|c|c|c|c|c|c|}
\hline Method & LOD & Multi-detection & Time & $\begin{array}{l}\text { Expe } \\
\text { requ }\end{array}$ & r devices & Refs. \\
\hline ELISA for $A \beta_{42}$ & $192 \mathrm{pg} / \mathrm{mL}$ & No & $3.5 \mathrm{~h}$ & Yes & [70] & \\
\hline ELISA for $A \beta_{42} \mathrm{Os}$ & $197 \mathrm{pg} / \mathrm{mL}$ & No & $3.5 \mathrm{~h}$ & Yes & {$[36]$} & \\
\hline Nanoparticles-based immunoassays & $163 \mathrm{pg} / \mathrm{mL}$ & No & $2 \mathrm{~h}$ & Yes & [71] & \\
\hline Surface-enhanced Raman spectroscopy & $181 \mathrm{ng} / \mathrm{mL}$ & No & NA & Yes & [39] & \\
\hline Fluorescence & $23 \mathrm{ng} / \mathrm{mL}$ & No & $4 \mathrm{~h}$ & Yes & [41] & \\
\hline Electrochemical biosensors & $2.26 \mathrm{ng} / \mathrm{mL}$ & No & $22 \mathrm{~h}$ & Yes & {$[37]$} & \\
\hline dLFI & $\begin{array}{l}\mathrm{A} \beta_{42} \mathrm{Ms}: 154 \mathrm{pg} / \mathrm{mL} \\
\mathrm{A} \beta_{42} \mathrm{Os}: 154 \mathrm{pg} / \mathrm{mL}\end{array}$ & Yes & $0.5 \mathrm{~h}$ & No & This work & \\
\hline
\end{tabular}

LOD, limit of detection; ELISA, enzyme-linked immunosorbent assay; dLFI, dual-target lateral flow immunoassay

$\mathrm{A} \beta_{42} \mathrm{Ms}$ appeared in the peripheral blood of $5 \mathrm{xFAD}$ mice at an early stage [e.g., 3-month-old 5xFAD mice had less $A \beta$ plaque load and Iba 1-positive cells staining (Fig. 4f, up)]; as the disease progresses, high levels of $A \beta_{42} \mathrm{Os}$ and insoluble $A \beta$ plaques were the main forms in the brain. As $A \beta_{42} \mathrm{Ms}$ in the brain gradually aggregated into $A \beta_{42}$ Os, soluble $A \beta_{42}$ could enter the blood, resulting in a decrease in $\mathrm{A} \beta_{42} \mathrm{Ms}$ level and an increase in $\mathrm{A} \beta_{42}$ Os level 
Table 2 Correlation of $A \beta_{42} \mathrm{Os}$ and $A \beta_{42} \mathrm{Ms}$ levels in blood samples with dLFI test

\begin{tabular}{llll}
\hline Samples & $\begin{array}{l}\text { Enriched } \mathbf{A} \boldsymbol{\beta}_{\mathbf{4 2}} \mathbf{M s} \\
(\mathbf{n g} / \mathbf{m L})\end{array}$ & $\begin{array}{l}\text { Enriched } \mathbf{A} \boldsymbol{\beta}_{42} \mathrm{Os} \\
(\mathbf{n g} / \mathbf{m L})\end{array}$ & dLFl test \\
\hline AD1 & 0.0302 & 0.3923 & -+ \\
AD2 & 0.0483 & 0.4273 & -+ \\
AD3 & 0.632 & 1.482 & ++ \\
AD4 & 0.223 & 0.2452 & -+ \\
AD5 & 0.9104 & 1.3293 & ++ \\
AD6 & 0.6382 & 0.4382 & ++ \\
AD7 & 0.2711 & 0.2704 & ++ \\
AD8 & 0.187 & 0.2113 & ++ \\
HC1 & 0.8204 & 0.0081 & +- \\
HC2 & 2.467 & 0.0080 & +- \\
HC3 & 0.6502 & 0.0028 & +- \\
HC4 & 0.728 & 0.0023 & +- \\
HC5 & 0.8213 & 0.0041 & +- \\
HC6 & 0.5781 & 0.0020 & +- \\
HC7 & 2.683 & 0.0051 & +- \\
\hline
\end{tabular}

Sandwich ELISA detects the levels of $A \beta_{42} M s$ and $A \beta_{42}$ Os in blood samples $A D$, Alzheimer's disease; $H C$, healthy controls; $A \beta_{42} M s$, $A \beta_{42}$ monomers; $A \beta_{42} \mathrm{Os}$, $A \beta_{42}$ oligomers; dLFI, dual-target lateral-flow immunoassay strip;,$-+ A \beta_{42} \mathrm{Ms}$ negative and $A \beta_{42}$ Os positive;,$++ A \beta_{42}$ Ms positive and $A \beta_{42}$ Os positive; +- . $A \beta_{42} \mathrm{Ms}$ positive and $A \beta_{42} \mathrm{Os}$ negative

[e.g., 9-month-old 5xFAD mice had more $\mathrm{A} \beta$ plaque load and Iba 1-positive cells staining (Fig. 4f, down)]. Of note, this elevated $A \beta_{42}$ Os level was closely related to the $A \beta$ plaque area (Fig. $4 \mathrm{~d}, \mathrm{p}<0.0001$ ) and soluble $A \beta_{42}$ level (Fig. $4 \mathrm{e}, \mathrm{p}<0.0001$ ) in the brain of $5 \mathrm{xFAD}$ mice, indicating that its level may reflect the progress of the disease. The phenomenon observed in 5xFAD mice was that the accumulation of $\mathrm{A} \beta_{42} \mathrm{Os}$ is directly accompanied by the decrease of $\mathrm{A} \beta_{42} \mathrm{Ms}$, consistent with the typical clinical symptoms of $A D$ patients [62-67]. Altogether, our results showed that $A \beta_{42}$ Os or $A \beta_{42}$ Ms that are mis-detected by commonly used ELISA are valuable biomarkers for AD diagnosis when they are accurately distinguished and detected.

\section{The performance of the dLFI in detecting $A \beta_{42} \mathrm{Os}$ and $A \beta_{42} M s$ in $A D$ patients}

To further improve the sensitivity and accuracy of the dLFI in the analysis of human blood samples, immunocapture magnetic beads were used to enrich the $\mathrm{A} \beta_{42} \mathrm{Os}$ and $A \beta_{42}$ Ms in samples (Fig. 5a). The unmodified MNPs were characterized and found to be approximately $190 \mathrm{~nm}$ (Additional file 1: Fig. S5a). After conjugation with 1F12, compared with bared MNPs, the size and Zeta potential of MNPs showed significant changes (Additional file 1: Fig. S5b-d). Furthermore, a 12\% reduced
SDS-PAGE gel showed two typical bonds, including the light and heavy chains observed in the lanes of $1 \mathrm{~F} 12$ and 1F12-MNPs, confirming the successful conjugation of 1F12 with MNPs (Fig. 5b). The biological activity of 1F12-MNPs was assessed by ELISA and IP-Western blotting. The results of ELISA (Fig. 5c) and IP-Western blotting (Fig. $5 \mathrm{~d}$ ) confirmed that 1F12-MNPs inherited the binding affinity of $1 \mathrm{~F} 12$ for $A \beta_{42} \mathrm{Ms}$ and $A \beta_{42}$ Os. After using dLFI to detect blood samples of $\mathrm{HC}(\mathrm{n}=7)$ and $\mathrm{AD}$ patients $(n=8)$, the results showed that the $A \beta_{42}$ Ms level of $\mathrm{HC}$ was significantly higher than that of $A D$ patients (Fig. 6a, left, black box, and Fig. 6b, $p=0.034$ ). In contrast, $\mathrm{A} \beta_{42} \mathrm{Os}$ were observed in $\mathrm{AD}$ patients, but not in HC (Fig. 6a, right, red box, and Fig. 6b, $p=0.039$ ). In addition, a sandwich ELISA test was performed using the enriched blood samples to evaluate the levels of $A \beta_{42} \mathrm{Ms}$ and $\mathrm{A} \beta_{42}$ Os. As shown in Fig. 6c, compared with blood samples from $\mathrm{HC}$, samples from $\mathrm{AD}$ patients showed a significant decrease in $\mathrm{A} \beta_{42} \mathrm{Ms}(p=0.0265)$ and an increase in $\mathrm{A} \beta_{42} \mathrm{Os}(p=0.086)$. This phenomenon is consistent with the clinical symptoms reported by multiple studies $[28,66,68,69]$.

To illustrate the ability of the dLFI in A $\beta$ detection, a horizontal comparison of various available technologies in Table 1, such as ELISA [36, 70], nanoparticles-based immunoassays [71], surface-enhanced Raman spectroscopy [39], fluorescence [41], electrochemical biosensors [37], etc. ELISA is mainly used as a stopgap measure with the highest sensitivity in $A \beta$ detection, but it cannot effectively distinguish monomers and oligomers. As shown in Fig. 6d, total $A \beta_{42}$ levels detected by sandwich ELISA using a pair of antibodies recognizing different epitopes of $A \beta_{42}$ showed no significant difference between $\mathrm{AD}$ and $\mathrm{HC}$ groups $(p=0.4837)$. Considering that the level of soluble $A \beta_{42} \mathrm{Os}$ in $\mathrm{AD}$ patients is elevated, it is easy to be mis-detected in the measurement of $A \beta_{42}$, resulting in the underestimation of $A \beta_{42}$ Ms level and poor performance in assessing the progression of $\mathrm{AD}$ $[36,72]$.

For nanoparticle-based immunoassays, including surface-enhanced Raman spectroscopy, fluorescence, and electrochemical biosensors, except for lacking the ability to distinguish monomers and oligomers, some special equipment and professional skills are required. On the contrary, dLFI can effectively detect monomers and oligomers by the naked eye within $30 \mathrm{~min}$, which is not only high sensitivity but also simple, user-friendly, and instant detection without special equipment and professional skills. Altogether, our results indicate that dLFI can simultaneously detect $\mathrm{A} \beta_{42} \mathrm{Ms}$ and $\mathrm{A} \beta_{42} \mathrm{Os}$ in patient blood samples, with high sensitivity and specificity (Table 2). 


\section{Conclusion}

This study provided a new method for the simultaneous detection of $A \beta_{42} \mathrm{Ms}$ and $\mathrm{A} \beta_{42} \mathrm{Os}$ in $\mathrm{AD}$ blood using effective and rapid multiple techniques. The dLFI could detect the levels of $A \beta_{42} \mathrm{Ms}$ and $A \beta_{42} \mathrm{Os}$ in the blood quickly (within $30 \mathrm{~min}$, including a 25-min enrichment step and a 5-min dLFI test step) and semi-quantitatively by naked eyes. In this system, the pre-incubation step can ensure high sensitivity and stability of the strip sensor. In conclusion, the dLFI allows high-throughput testing of small samples and has the potential to become a powerful tool for the rapid and accurate diagnosis of AD.

\section{Supplementary Information}

The online version contains supplementary material available at https://doi. org/10.1186/s12951-021-01111-z.

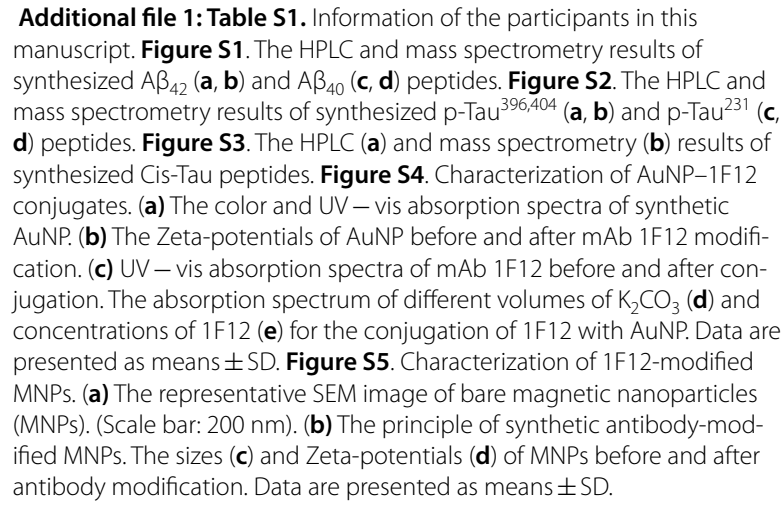
synthesized $A \beta_{42}(\mathbf{a}, \mathbf{b})$ and $A \beta_{40}(\mathbf{c}, \mathbf{d})$ peptides. Figure $\mathbf{S 2}$. The HPLC and mass spectrometry results of synthesized p-Tau ${ }^{396,404}(\mathbf{a}, \mathbf{b})$ and p-Tau ${ }^{231}(\mathbf{c}$, d) peptides. Figure S3. The HPLC (a) and mass spectrometry (b) results of synthesized Cis-Tau peptides. Figure S4. Characterization of AuNP-1F12 conjugates. (a) The color and UV - vis absorption spectra of synthetic AuNP. (b) The Zeta-potentials of AuNP before and after mAb 1 F12 modification. (c) UV - vis absorption spectra of mAb $1 \mathrm{~F} 12$ before and after conjugation. The absorption spectrum of different volumes of $\mathrm{K}_{2} \mathrm{CO}_{3}(\mathbf{d})$ and concentrations of $1 \mathrm{~F} 12$ (e) for the conjugation of 1F12 with AuNP. Data are presented as means \pm SD. Figure S5. Characterization of 1F12-modified MNPs. (a) The representative SEM image of bare magnetic nanoparticles (MNPs). (Scale bar: $200 \mathrm{~nm}$ ). (b) The principle of synthetic antibody-modified MNPs. The sizes (c) and Zeta-potentials (d) of MNPs before and after antibody modification. Data are presented as means \pm SD.

\section{Acknowledgements}

We thank the associate professor Jinyang Zhang, Kunming University of Science and Technology, for his technical support for the screening of monoclonal antibodies. We also thank the Engineering Research Center of Nano-Geomaterials of the Ministry of Education and the Center for Nanoscale Characterization \& Devices (CNCD) of WNLO-HUST for support with data acquisition and the Analytical and Testing Center of HUST for performing spectral measurements.

\section{Authors' contributions}

LH ordinated the writing of the paper and provided writing guidance and manuscript revision. ZL and DX completed all experiments and contributed to writing the first draft. SY provided AD patient blood samples and helped analyze the test results, as well as clinical diagnosis of AD patients and helped analyze the test results, as well as clinical diagnosis of AD patients. LY and NS participated in most experiments. LX was involved in 5xFAD mice breeding and schematic figure preparations. All authors read and approved the final manuscript.

\section{Funding}

This work was supported by the Major Research Plan of the National Natural Science Foundation of China (Grant No. 91749209), the National Natural Science Foundation of China (Grant No. 81971025), the Fundamental Research Funds for the Central Universities in HUST (2019kfyXKJC076), and Hubei Provincial Natural Science Foundation (2020CFB811).

\section{Declarations}

\section{Ethics approval and consent to participate}

All procedures involving experimental animals were carried out under guidelines approved by the Institutional Animal Care and Use Committee of Huazhong University of Science and Technology.

\section{Consent for publication}

Not applicable.

\section{Competing interests}

The authors declare no conflict of interest, financial or otherwise.

\section{Author details}

${ }^{1}$ Britton Chance Center for Biomedical Photonics, Wuhan National Laboratory for Optoelectronics, Huazhong University of Science and Technology, Wuhan, China. ${ }^{2}$ MoE Key Laboratory for Biomedical Photonics, School of Engineering Sciences, Huazhong University of Science and Technology, Wuhan, China. ${ }^{3}$ Engineering Research Center of Nano-Geomaterials of Ministry of Education, Faculty of Materials Science and Chemistry, China University of Geosciences, Wuhan, China. ${ }^{4}$ Department of Neurology, Union Hospital, Tongji Medical College, Huazhong University of Science and Technology, Wuhan 430022, China. ${ }^{5}$ Wuhan, China.

Received: 13 September 2021 Accepted: 2 November 2021

Published online: 17 November 2021

\section{References}

1. McDade E, Bateman RJ. Stop Alzheimer's before it starts. Nature. 2017:547:153-5.

2. Lane CA, Hardy J, Schott JM. Alzheimer's disease. Eur J Neurol. 2018;25:59-70.

3. Blennow K, de Leon MJ, Zetterberg H. Alzheimer's disease. Lancet. 2006;368:387-403.

4. Ittner LM, Gotz J. Amyloid-beta and tau - a toxic pas de deux in Alzheimer's disease. Nat Rev Neurosci. 2011;12:65-72.

5. Citron M. Strategies for disease modification in Alzheimer's disease. Nat Rev Neurosci. 2004;5:677-85.

6. Brunden KR, Trojanowski JQ, Lee VM. Advances in tau-focused drug discovery for Alzheimer's disease and related tauopathies. Nat Rev Drug Discov. 2009;8:783-93.

7. Lee D, Kim SM, Kim HY, Kim Y. Fluorescence chemicals to detect insoluble and soluble amyloid- $\beta$ aggregates. ACS Chem Neurosci. 2019;10:2647-57.

8. Duan Y, Chen J, Jin Y, Tu Q, Wang S, Xiang J. Antibody-free determinations of low-mass, soluble oligomers of $A \beta(42)$ and $A \beta(40)$ by planar bilayer lipid membrane-based electrochemical biosensor. Anal Chem. 2021;93:3611-7.

9. Jia Y, Yang L, Feng R, Ma H, Fan D, Yan T, Feng R, Du B, Wei Q. MnCO(3) as a new electrochemiluminescence emitter for ultrasensitive bioanalysis of $\beta$-amyloid(1-42) oligomers based on site-directed immobilization of antibody. ACS Appl Mater Interfaces. 2019;11:7157-63.

10. Jack CR Jr. Alzheimer disease: new concepts on its neurobiology and the clinical role imaging will play. Radiology. 2012;263:344-61.

11. Jack CR Jr, Wiste HJ, Schwarz CG, Lowe VJ, Senjem ML, Vemuri P, Weigand SD, Therneau TM, Knopman DS, Gunter JL, et al. Longitudinal tau PET in ageing and Alzheimer's disease. Brain. 2018;141:1517-28.

12. Mueller A, Bullich S, Barret O, Madonia J, Berndt M, Papin C, Perrotin A, Koglin N, Kroth H, Pfeifer A, et al. Tau PET imaging with (18)F-PI-2620 in patients with Alzheimer disease and healthy controls: a first-in-humans study. J Nucl Med. 2020;61:911-9.

13. Rowe CC, Ellis KA, Rimajova M, Bourgeat P, Pike KE, Jones G, Fripp J, Tochon-Danguy H, Morandeau L, O'Keefe G, et al. Amyloid imaging results from the Australian Imaging, Biomarkers and Lifestyle (AIBL) study of aging. Neurobiol Aging. 2010;31:1275-83.

14. Lee JC, Kim SJ, Hong S, Kim Y. Diagnosis of Alzheimer's disease utilizing amyloid and tau as fluid biomarkers. Exp Mol Med. 2019;51:1-10.

15. Janelidze S, Mattsson N, Palmqvist S, Smith R, Beach TG, Serrano GE, Chai X, Proctor NK, Eichenlaub U, Zetterberg H, et al. Plasma P-tau181 
in Alzheimer's disease: relationship to other biomarkers, differential diagnosis, neuropathology and longitudinal progression to Alzheimer's dementia. Nat Med. 2020;26:379-86.

16. Thijssen EH, La Joie R, Strom A, Fonseca C, laccarino L, Wolf A, Spina S, Allen IE, Cobigo Y, Heuer H, et al. Plasma phosphorylated tau 217 and phosphorylated tau 181 as biomarkers in Alzheimer's disease and frontotemporal lobar degeneration: a retrospective diagnostic performance study. Lancet Neurol. 2021;20:739-52.

17. Kang JH, Korecka M, Toledo JB, Trojanowski JQ, Shaw LM. Clinical utility and analytical challenges in measurement of cerebrospinal fluid amyloid- $\beta(1-42)$ and t proteins as Alzheimer disease biomarkers. Clin Chem. 2013;59:903-16.

18. Zhong Y, Shobo A, Hancock MA, Multhaup G. Label-free distribution of anti-amyloid D-AIP in Drosophila melanogaster: prevention of Abeta42induced toxicity without side effects in transgenic flies. J Neurochem. 2019;150:74-87

19. Hughes C, Choi ML, Yi JH, Kim SC, Drews A, George-Hyslop PS, Bryant C, Gandhi S, Cho K, Klenerman D. Beta amyloid aggregates induce sensitised TLR4 signalling causing long-term potentiation deficit and rat neuronal cell death. Commun Biol. 2020;3:79.

20. He N, Jin WL, Lok KH, Wang Y, Yin M, Wang ZJ. Amyloid-beta(1-42) oligomer accelerates senescence in adult hippocampal neural stem/progenitor cells via formylpeptide receptor 2. Cell Death Dis. 2013;4: e924.

21. Hampel H, Vassar R, De Strooper B, Hardy J, Willem M, Singh N, Zhou J, Yan R, Vanmechelen E, De Vos A, et al. The beta-secretase BACE1 in Alzheimer's disease. Biol Psychiatry. 2021;89:745-56.

22. Bullich S, Seibyl J, Catafau AM, Jovalekic A, Koglin N, Barthel H, Sabri O, De Santi S. Optimized classification of (18)F-Florbetaben PET scans as positive and negative using an SUVR quantitative approach and comparison to visual assessment. Neuroimage Clin. 2017;15:325-32.

23. Morris E, Chalkidou A, Hammers A, Peacock J, Summers J, Keevil S. Diagnostic accuracy of $18 \mathrm{~F}$ amyloid PET tracers for the diagnosis of Alzheimer's disease: a systematic review and meta-analysis. Eur J Nucl Med Mol Imaging. 2016;43:374-85.

24. Madhavan A, Whitwell JL, Weigand SD, Duffy JR, Strand EA, Machulda MM, Tosakulwong N, Senjem ML, Gunter JL, Lowe VJ, et al. FDG PET and MRI in logopenic primary progressive aphasia versus dementia of the Alzheimer's type. PLoS ONE. 2013;8: e62471.

25. Le Ngoc HT, Park J, Chinnadayyala SR, Cho S. Sensitive electrochemical detection of amyloid beta peptide in human serum using an interdigitated chain-shaped electrode. Biosens Bioelectron. 2019;144: 111694.

26. Le HTN, Kim D, Phan LMT, Cho S. Ultrasensitive capacitance sensor to detect amyloid-beta 1-40 in human serum using supramolecular recognition of $\beta-C D / R G O / I T O$ micro-disk electrode. Talanta. 2021;237: 122907.

27. Liu L, Kwak H, Lawton TL, Jin SX, Meunier AL, Dang Y, Ostaszewski B, Pietras $A C$, Stern AM, Selkoe DJ. An ultra-sensitive immunoassay detects and quantifies soluble $A \beta$ oligomers in human plasma. Alzheimers Dement. 2021. https://doi.org/10.1002/alz.12457.

28. Nakamura A, Kaneko N, Villemagne VL, Kato T, Doecke J, Doré V, Fowler C, Li QX, Martins R, Rowe C, et al. High performance plasma amyloid- $\beta$ biomarkers for Alzheimer's disease. Nature. 2018;554:249-54.

29. Cintron AF, Dalal NV, Dooyema J, Betarbet R, Walker LC. Transport of cargo from periphery to brain by circulating monocytes. Brain Res. 2015;1622:328-38.

30. Boluda S, Iba M, Zhang B, Raible KM, Lee VM, Trojanowski JQ. Differential induction and spread of tau pathology in young PS19 tau transgenic mice following intracerebral injections of pathological tau from Alzheimer's disease or corticobasal degeneration brains. Acta Neuropathol. 2015;129:221-37

31. Ye L, Hamaguchi T, Fritschi SK, Eisele YS, Obermüller U, Jucker M, Walker $L C$. Progression of seed-induced $A \beta$ deposition within the limbic connectome. Brain Pathol. 2015;25:743-52.

32. Lakshmi S, Essa MM, Hartman RE, Guillemin GJ, Sivan S, Elumalai P. Exosomes in Alzheimer's disease: potential role as pathological mediators biomarkers and therapeutic targets. Neurochem Res. 2020;45:2553-9.

33. Jia L, Qiu Q, Zhang H, Chu L, Du Y, Zhang J, Zhou C, Liang F, Shi S, Wang S, et al. Concordance between the assessment of A 42, T-tau, and P-T181tau in peripheral blood neuronal-derived exosomes and cerebrospinal fluid. Alzheimers Dement. 2019;15:1071-80.

34. Dickerson BC, Bakkour A, Salat DH, Feczko E, Pacheco J, Greve DN, Grodstein F, Wright Cl, Blacker D, Rosas HD, et al. The cortical signature of Alzheimer's disease: regionally specific cortical thinning relates to symptom severity in very mild to mild AD dementia and is detectable in asymptomatic amyloid-positive individuals. Cereb Cortex. 2009;19:497-510

35. Stenh C, Englund H, Lord A, Johansson AS, Almeida CG, Gellerfors $P$, Greengard P, Gouras GK, Lannfelt L, Nilsson LN. Amyloid-beta oligomers are inefficiently measured by enzyme-linked immunosorbent assay. Ann Neurol. 2005;58:147-50.

36. Yang T, Hong S, O'Malley T, Sperling RA, Walsh DM, Selkoe DJ. New ELISAs with high specificity for soluble oligomers of amyloid $\beta$-protein detect natural $A \beta$ oligomers in human brain but not CSF. Alzheimers Dement. 2013;9:99-112.

37. Li H, Xie H, Cao Y, Ding X, Yin Y, Li G. A general way to assay protein by coupling peptide with signal reporter via supermolecule formation. Anal Chem. 2013;85:1047-52.

38. Liu L, Xia N, Jiang M, Huang N, Guo S, Li S, Zhang S. Electrochemical detection of amyloid- $\beta$ oligomer with the signal amplification of alkaline phosphatase plus electrochemical-chemical-chemical redox cycling. J Electroanal Chem. 2015;754:40-5.

39. Guerrini L, Arenal R, Mannini B, Chiti F, Pini R, Matteini P, Alvarez-Puebla RA. SERS detection of amyloid oligomers on metallorganic-decorated plasmonic beads. ACS Appl Mater Interfaces. 2015;7:9420-8.

40. Zhu W, Wang Y, Xie D, Cheng L, Wang P, Zeng Q, Li M, Zhao Y. In situ monitoring the aggregation dynamics of amyloid- $\beta$ protein $A \beta 42$ in physiological media via a Raman-based frequency shift method. ACS Appl Bio Mater. 2018;1:814-24.

41. Zhu L, Zhang J, Wang F, Wang Y, Lu L, Feng C, Xu Z, Zhang W. Selective amyloid $\beta$ oligomer assay based on abasic site-containing molecular beacon and enzyme-free amplification. Biosens Bioelectron. 2016;78:206-12.

42. Rushworth JV, Ahmed A, Griffiths HH, Pollock NM, Hooper NM, Millner PA. A label-free electrical impedimetric biosensor for the specific detection of Alzheimer's amyloid-beta oligomers. Biosens Bioelectron. 2014;56:83-90.

43. Veloso AJ, Chow AM, Ganesh HV, Li N, Dhar D, Wu DC, Mikhaylichenko S, Brown IR, Kerman K. Electrochemical immunosensors for effective evaluation of amyloid-beta modulators on oligomeric and fibrillar aggregation processes. Anal Chem. 2014;86:4901-9.

44. Wang Y, Deng R, Zhang G, Li Q, Yang J, Sun Y, Li Z, Hu X. Rapid and sensitive detection of the food allergen glycinin in powdered milk using a lateral flow colloidal gold immunoassay strip test. J Agric Food Chem. 2015;63:2172-8.

45. Hong L, Wang K, Yan W, Xu H, Chen Q, Zhang Y, Cui D, Jin Q, He J. High performance immunochromatographic assay for simultaneous quantitative detection of multiplex cardiac markers based on magnetic nanobeads. Theranostics. 2018;8:6121-31.

46. Gao F, Lei C, Liu Y, Song H, Kong Y, Wan J, Yu C. Rational design of dendritic mesoporous silica nanoparticles' surface chemistry for quantum dot enrichment and an ultrasensitive lateral flow immunoassay. ACS Appl Mater Interfaces. 2021;13:21507-15.

47. Goryacheva OA, Guhrenz C, Schneider K, Beloglazova NV, Goryacheva IY, De Saeger S, Gaponik N. Silanized luminescent quantum dots for the simultaneous multicolor lateral flow immunoassay of two mycotoxins. ACS Appl Mater Interfaces. 2020;12:24575-84.

48. Zhang LLX, Zhang Z, Luo H. Cerebrospinal fluid and blood biomarkers in the diagnostic assays of Alzheimer's disease. J Innov Opt Health Sci. 2021. https://doi.org/10.1142/S1793545822300014.

49. Counts SE, Ikonomovic MD, Mercado N, Vega IE, Mufson EJ. Biomarkers for the early detection and progression of Alzheimer's disease. Neurotherapeutics. 2017;14:35-53.

50. Blennow K, Hampel H. CSF markers for incipient Alzheimer's disease. Lancet Neurol. 2003;2:605-13.

51. Zhang L, Yang C, Li Y, Niu S, Liang $X$, Zhang Z, Luo Q, Luo H. Dynamic changes in the levels of amyloid- $\beta 42$ species in the brain and periphery of APP/PS1 mice and their significance for Alzheimer's disease. Front Mol Neurosci. 2021;14: 723317.

52. Verma HN, Singh P, Chavan R. Gold nanoparticle: synthesis and characterization. Vet World. 2014;7:72.

53. Zhang L, Shi Y, Chen C, Han Q, Chen Q, Xia X, Song Y, Zhang J. Rapid, visual detection of klebsiella pneumoniae using magnetic nanoparticles and an horseradish peroxidase-probe based immunosensor. J Biomed Nanotechnol. 2019;15:1061-71. 
54. Mena R, Edwards P, Pérez-Olvera O, Wischik CM. Monitoring pathologica assembly of tau and beta-amyloid proteins in Alzheimer's disease. Acta Neuropathol. 1995;89:50-6.

55. Sun A, Nguyen XV, Bing G. Comparative analysis of an improved thioflavin-s stain, Gallyas silver stain, and immunohistochemistry for neurofibrillary tangle demonstration on the same sections. J Histochem Cytochem. 2002;50:463-72

56. Luna-Muñoz J, Peralta-Ramirez J, Chávez-Macías L, Harrington CR, Wischik CM, Mena R. Thiazin red as a neuropathological tool for the rapid diagnosis of Alzheimer's disease in tissue imprints. Acta Neuropathol. 2008;116:507-15.

57. Bagchi P, Birnbaum SM. Effect of $\mathrm{pH}$ on the adsorption of immunoglobulin $\mathrm{G}$ on anionic poly(vinyltoluene) model latex particles. J Colloid Interface Sci. 1981;83:460-78.

58. Demanèche $S$, Chapel JP, Monrozier LJ, Quiquampoix H. Dissimilar $\mathrm{pH}$-dependent adsorption features of bovine serum albumin and alphachymotrypsin on mica probed by AFM. Colloids Surf B Biointerfaces. 2009;70:226-31.

59. Peng ZG, Hidajat $K$, Uddin MS. Adsorption of bovine serum albumin on nanosized magnetic particles. J Colloid Interface Sci. 2004;271:277-83.

60. Ruppert C, Kaiser L, Jacob LJ, Laufer S, Kohl M, Deigner HP. Duplex Shiny app quantification of the sepsis biomarkers $C$-reactive protein and interleukin-6 in a fast quantum dot labeled lateral flow assay. J Nanobiotechnol. 2020;18:130.

61. Kim HM, Kim J, An J, Bock S, Pham XH, Huynh KH, Choi Y, Hahm E, Song $\mathrm{H}$, Kim JW, et al. Au-Ag assembled on silica nanoprobes for visual semiquantitative detection of prostate-specific antigen. J Nanobiotechnol. 2021;19:73.

62. Motter R, Vigo-Pelfrey C, Kholodenko D, Barbour R, Johnson-Wood K, Galasko D, Chang L, Miller B, Clark C, Green R, et al. Reduction of betaamyloid peptide42 in the cerebrospinal fluid of patients with Alzheimer's disease. Ann Neurol. 1995;38:643-8.

63. Englund $H$, Sehlin D, Johansson AS, Nilsson LN, Gellerfors P, Paulie $S$, Lannfelt L, Pettersson FE. Sensitive ELISA detection of amyloid-beta protofibrils in biological samples. J Neurochem. 2007:103:334-45.

64. Wang MJ, Yi S, Han JY, Park SY, Jang JW, Chun IK, Kim SE, Lee BS, Kim GJ, Yu $J S$, et al. Oligomeric forms of amyloid- $\beta$ protein in plasma as a potential blood-based biomarker for Alzheimer's disease. Alzheimers Res Ther. 2017;9:98
65. Babapour Mofrad R, Scheltens P, Kim S, Kang S, Youn YC, An SSA, Tomassen J, van Berckel BNM, Visser PJ, van der Flier WM, Teunissen CE. Plasma amyloid- $\beta$ oligomerization assay as a pre-screening test for amyloid status. Alzheimers Res Ther. 2021;13:133.

66. Nabers A, Ollesch J, Schartner J, Kötting C, Genius J, Hafermann H, Klafk $H$, Gerwert K, Wiltfang J. Amyloid- $\beta$-secondary structure distribution in cerebrospinal fluid and blood measured by an immuno-infraredsensor: a biomarker candidate for Alzheimer's disease. Anal Chem. 2016;88:2755-62.

67. Kim Y, Yoo YK, Kim HY, Roh JH, Kim J, Baek S, Lee JC, Kim HJ, Chae MS, Jeong $D$, et al. Comparative analyses of plasma amyloid- $\beta$ levels in heterogeneous and monomerized states by interdigitated microelectrode sensor system. Sci Adv. 2019;5: eaav1388.

68. Zhang J, Peng M, Jia J. Plasma amyloid- $\beta$ oligomers and soluble tumor necrosis factor receptors as potential biomarkers of AD. Curr Alzheimer Res. 2014;11:325-31.

69. Verberk IMW, Slot RE, Verfaillie SCJ, Heijst H, Prins ND, van Berckel BNM. Plasma amyloid as pre-screener for the earliest Alzheimer's pathological changes. Ann Neurol. 2018;138:1328-36.

70. Shaw LM, Vanderstichele H, Knapik-Czajka M, Clark CM, Aisen PS, Petersen RC, Blennow K, Soares H, Simon A, Lewczuk P, et al. Cerebrospinal fluid biomarker signature in Alzheimer's disease neuroimaging initiative subjects. Ann Neurol. 2009;65:403-13.

71. Jiang LF, Chen BC, Chen B, Li XJ, Liao HL, Huang HM, Guo ZJ, Zhang WY, Wu L. Detection of A oligomers based on magnetic-field-assisted separation of aptamer-functionalized $\mathrm{Fe}(3) \mathrm{O}(4)$ magnetic nanoparticles and BaYF(5):Yb, Er nanoparticles as upconversion fluorescence labels. Talanta. 2017;170:350-7.

72. Liu L, Chang Y, Yu J, Jiang M, Xia N. Two-in-one polydopamine nanospheres for fluorescent determination of beta-amyloid oligomers and inhibition of beta-amyloid aggregation. Sens Actuators B. 2017;251:359-65.

\section{Publisher's Note}

Springer Nature remains neutral with regard to jurisdictional claims in published maps and institutional affiliations.
Ready to submit your research? Choose BMC and benefit from:

- fast, convenient online submission

- thorough peer review by experienced researchers in your field

- rapid publication on acceptance

- support for research data, including large and complex data types

- gold Open Access which fosters wider collaboration and increased citations

- maximum visibility for your research: over $100 \mathrm{M}$ website views per year

At BMC, research is always in progress.

Learn more biomedcentral.com/submissions 